Historic, archived document

Do not assume content reflects current scientific knowledge, policies, or practices. 


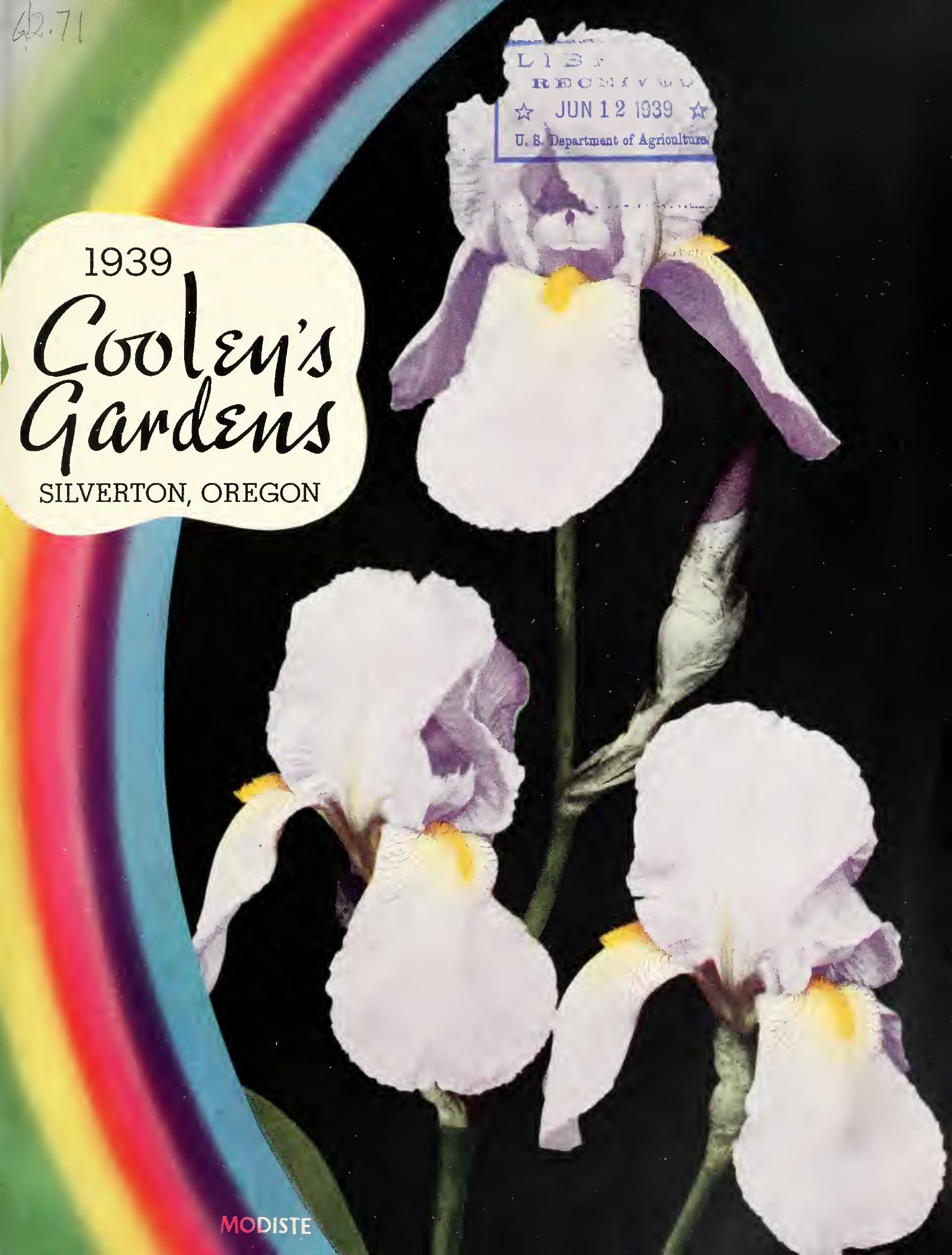



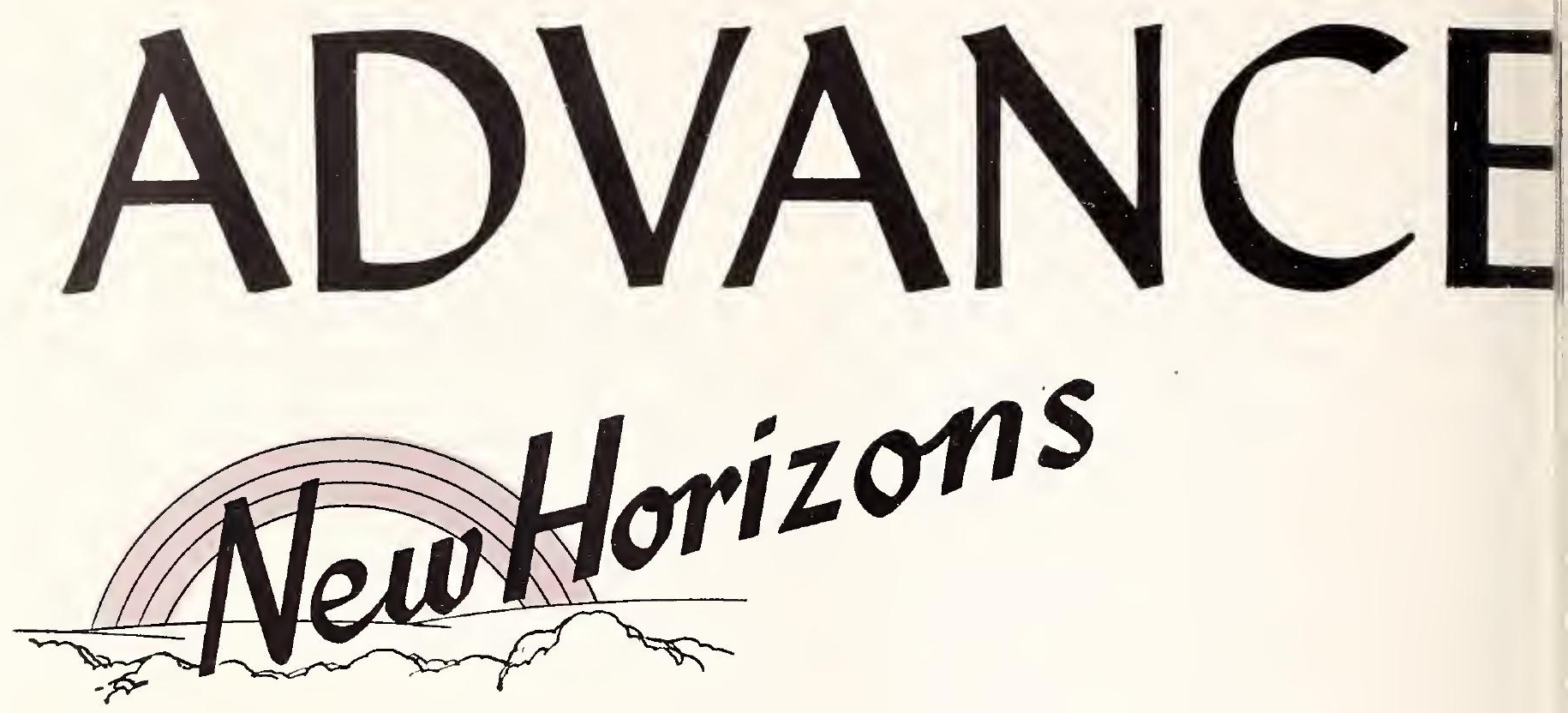

If you would paint your landscape with brilliance, or with bewitching pastel tints; if you wish colorful border clumps, or if you grow your flowers for cutting and indoor enjoyment, the Iris, in some form or species, will fill the need. The collecting of fine irises, like the accumulating of rare paintings or antiques, is a fascinating and inspiring hobby. And best of all, no group of flowers presents fewer obstacles to success.

Take a step forward and treat yourself to the thrill and satisfaction of owning and growing some - or at least one - real novelty iris.

As you would regard an opera performance, or a ticket to the world's series, or an object d'art for the home, so is one of the recent new irises an acquisition to be treasured, and one in which you will experience a rare feeling of pride in owning.

For your friend who gardens, it is the gift supreme!

Among the world's finest and most varied collections is the planting in our gardens. The beginner with flowers, with only a small sum to spend, will find a wealth of beauty obtainable for a modest outlay. And likewise, the estate owner and others to whom expense is a secondary consideration will find the ultimate in rarity and perfection offered within these pages.

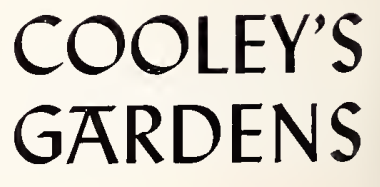

Silverton, Oregon 


\section{New for 1939}

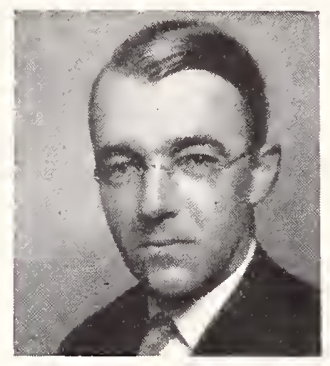

\section{FROM DR. R. E. KLEINSORGE}

This year we offer three most distinct new color innovations: AZTEC COPPER, BUCKSKIN, and OLD PARCHMENT. The doctor has been growing and hybridizing iris for more than 15 years, and is known for such things as Kalinga, Itasca, Far West, Treasure Island, and the great Ormohr, all of which rank as milestones in iris breeding.

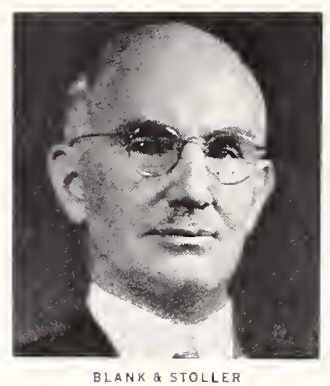

\section{FROM DAVID HALL}

Mr. Hall, an attorney residing in the suburbs of Chicago, has the iris world agog with his most recent seedlings. His MODISTE won the Highly Commended award in 1937, and last year scores of competent judges visiting his garden were astounded by the high quality of his newer things. We offer herewith four of these: BERMUDA SAND, ROSELAND, TOKEN, and VICTORY. Mr. Hall is one of the Directors of the American Iris Society.

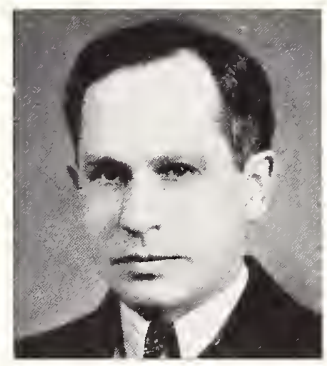

\section{FROM E. G. LAPHAM}

An Elkhart, Indiana, rubber manufacturer, who toys with iris solely for pleasure and has produced such reds as Jerry and Christabel, and the well known pinks, Eloise Lapham and Ethelwyn Dubuar. He is a prominent iris judge whose services are in wide demand each season, and is a member of the Editorial Board of the American Iris Society. This year we bring you his fiery RED GLEAM and the exquisite SPRING IDYL.

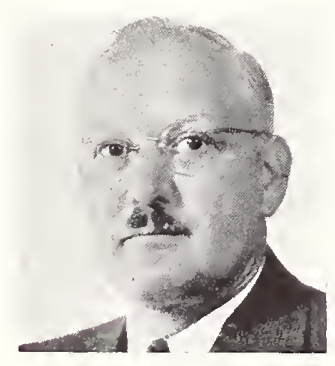

\section{FROM DR. A. C. WILHELM}

Another Chicago resident who has recently advanced to the forefront with his productions. Dr. Wilhelm is an optometrist whose hobby for many years has been iris. He grows them by the acre without thought of remuneration other than the pleasure of seeing them bloom and the joy of creating something new and worthy. His STAINED GLASS is unique and is the first one of his thousands of seedlings to be introduced.

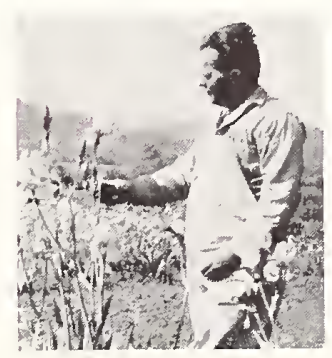

\section{FROM FRED DE FOREST}

Tucked away in the little story-book hamlet of Alpine, Oregon, we found a collection of seedlings of exceptional merit produced by a man who lives and breathes and thinks naught but iris while pursuing his daily farm routine. Two of them, GOLDEN SLIPPERS and GLOWPORT, appear on the following pages, and are offered at ridiculously low prices that you may easily acquaint yourself with the work of this newcomer to the introducer's ranks. 


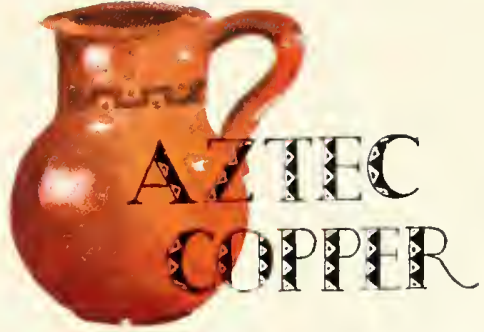

Ever on the alert for an entirely new departure in iris color, the iris grower who thought the end of the road was close at hand will experience a tremendous thrill when first his gaze alights on AZTEC COPPER! A rare and subtle blend of smokey violets and subdued coppers, blended and washed together in lovely harmony to baffle description. A positively huge flower with broad hafts and leathery substance, wonderfully branched. 36 to 40 inches.

Each $\$ 25.00$

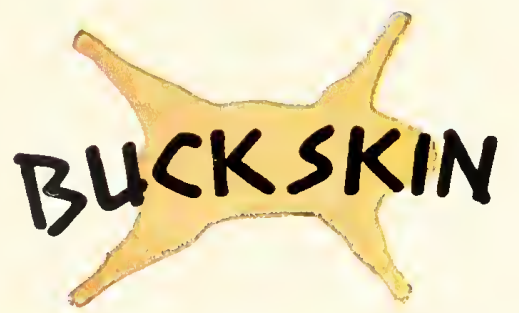

Note the ideal shape and fine carriage of this new and aptly named tan self. The stalks rise to a height of four feet, bearing close to a dozen great blooms with large closed standards and wide flaring falls. This is far and away ahead of other tan iris now on the market, a remarkable color to use with the blues, yellows, creams, or bronzy reds.

Each $\$ 10.00$

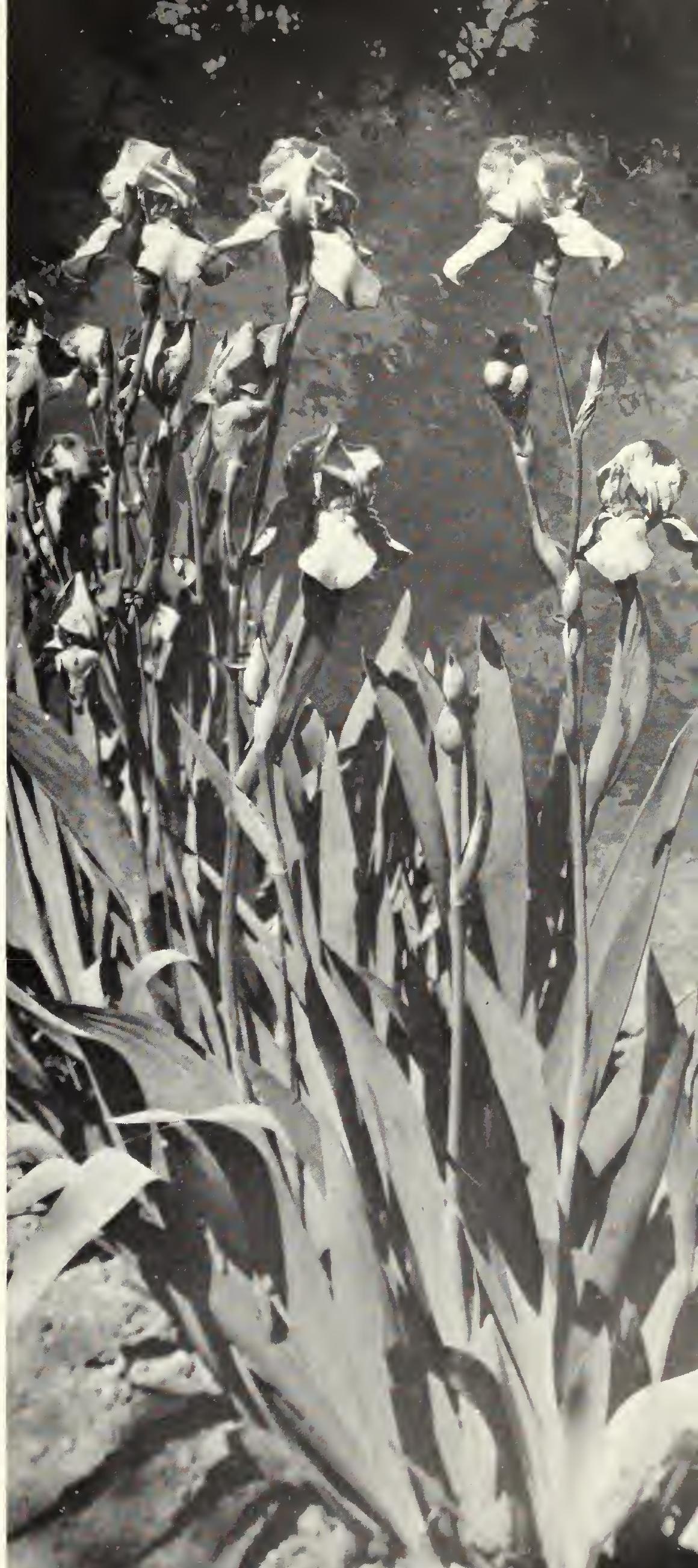




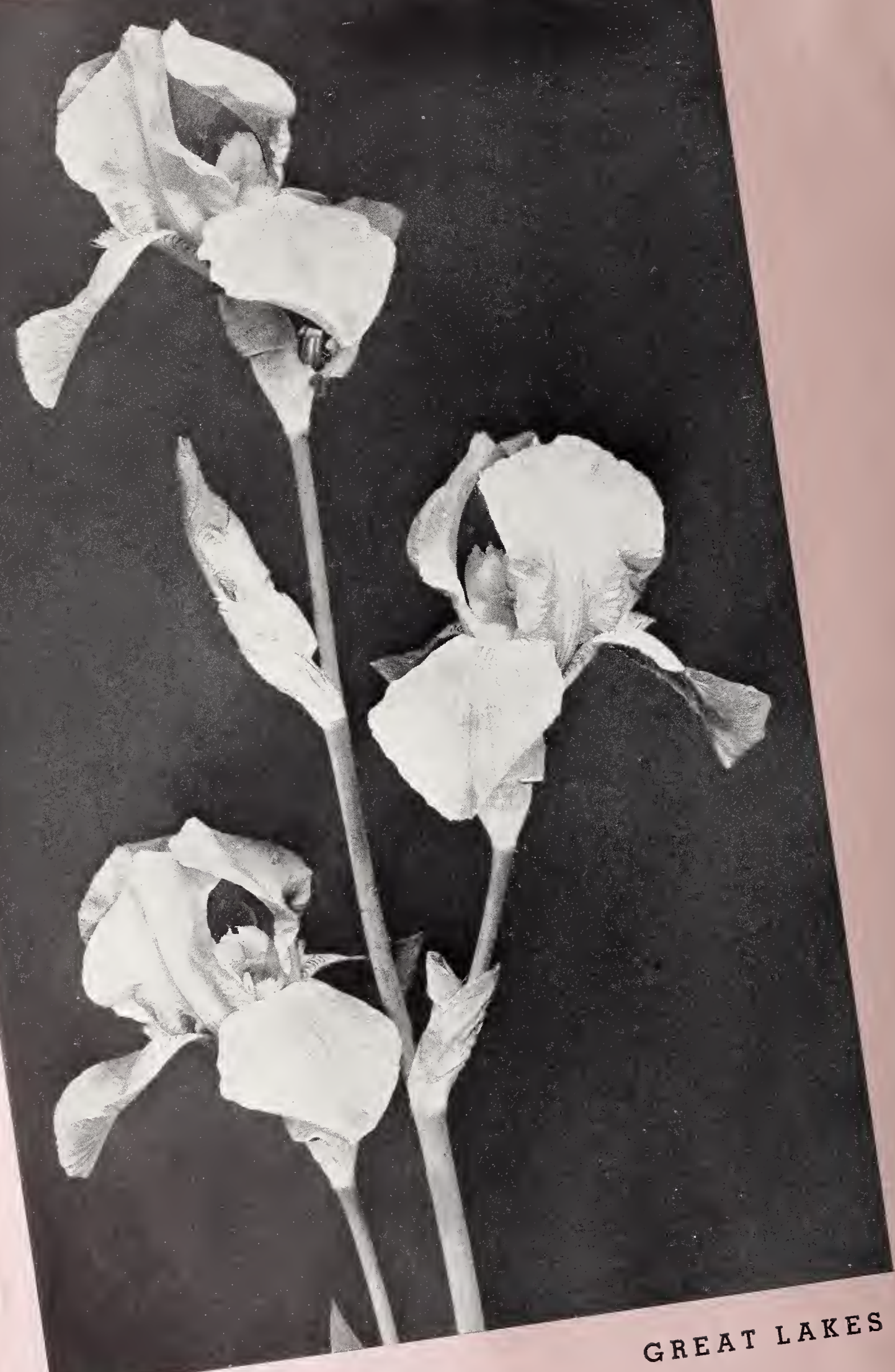




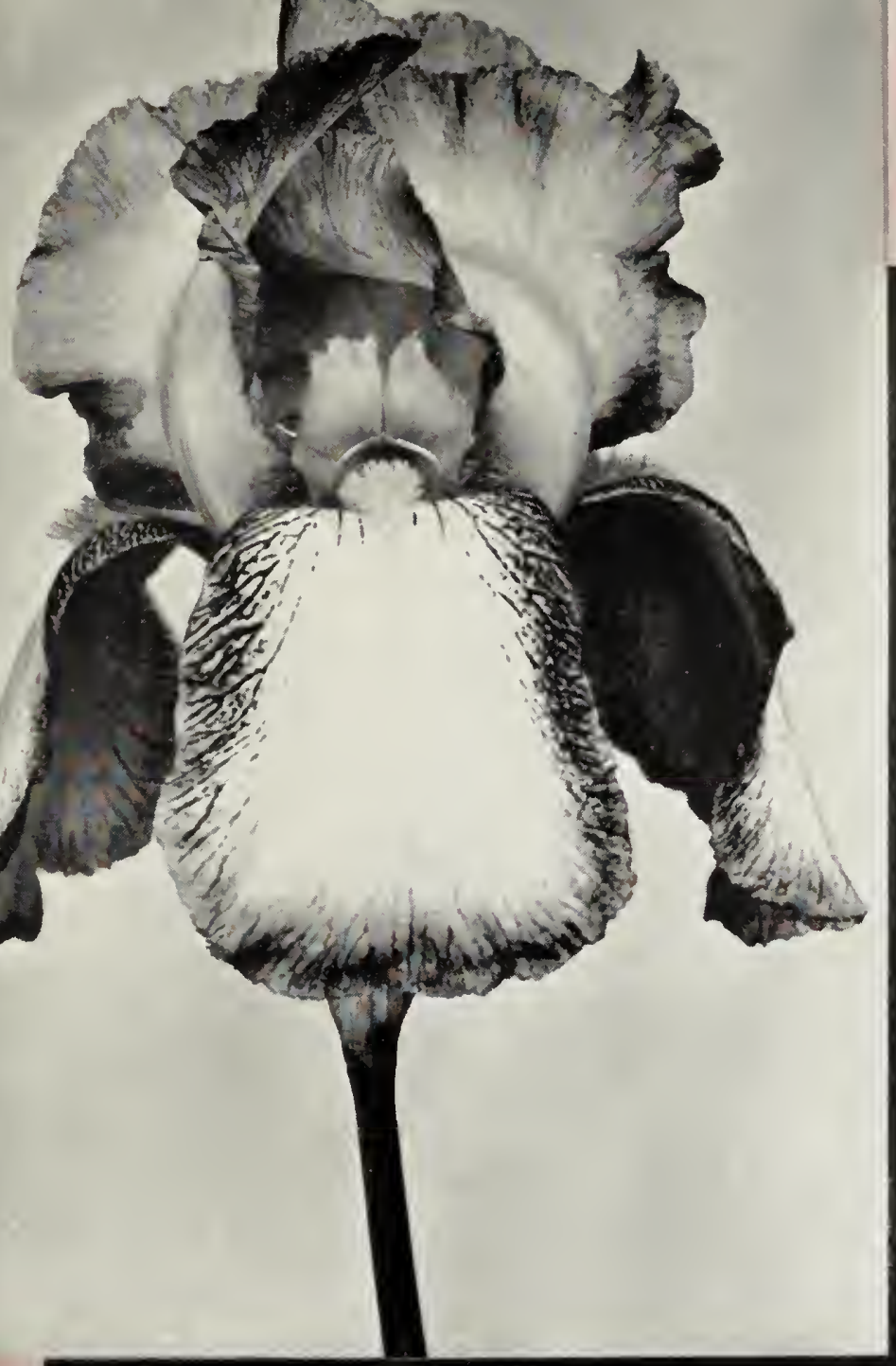

S I E G F R I E D

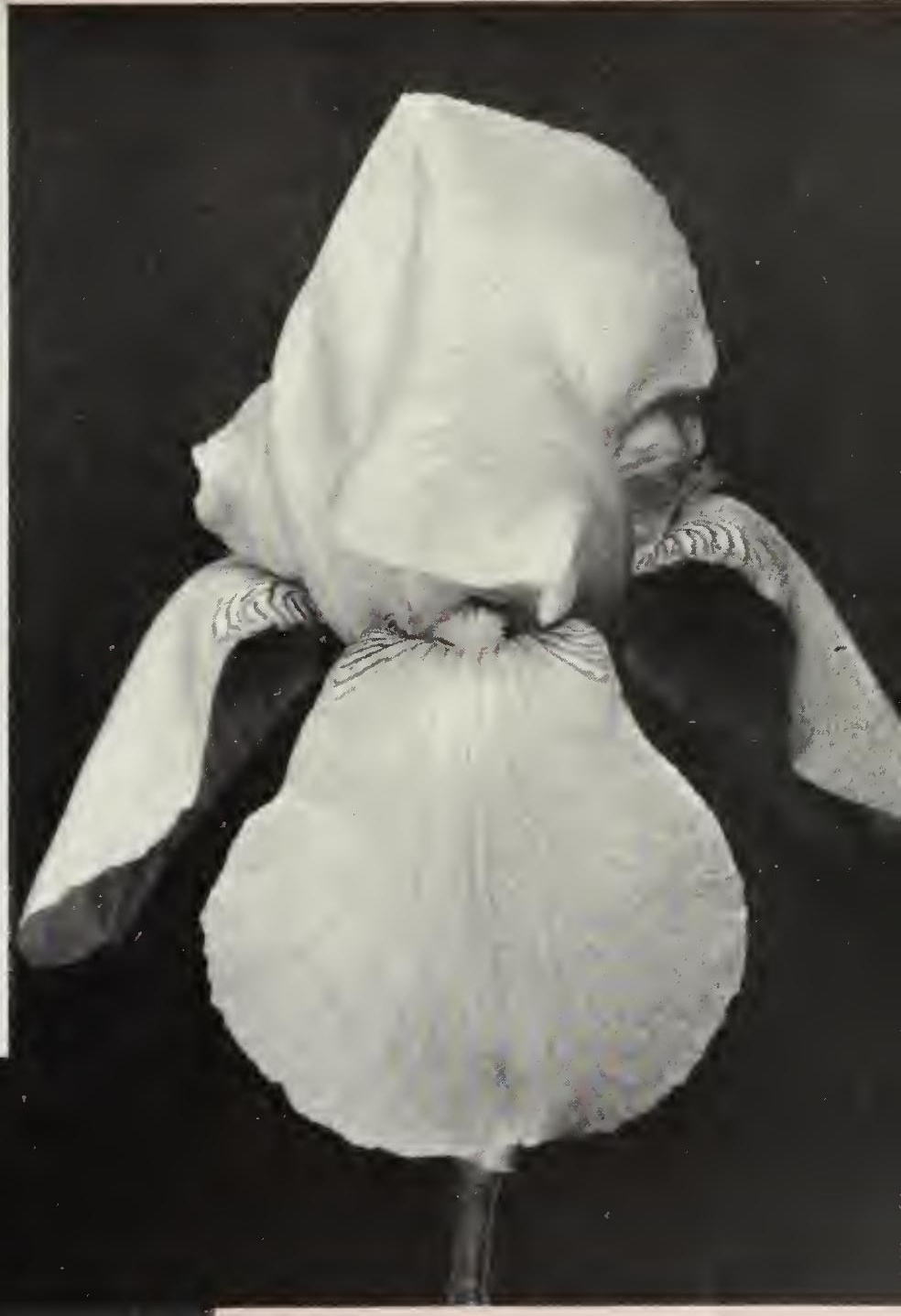

A N I T R A

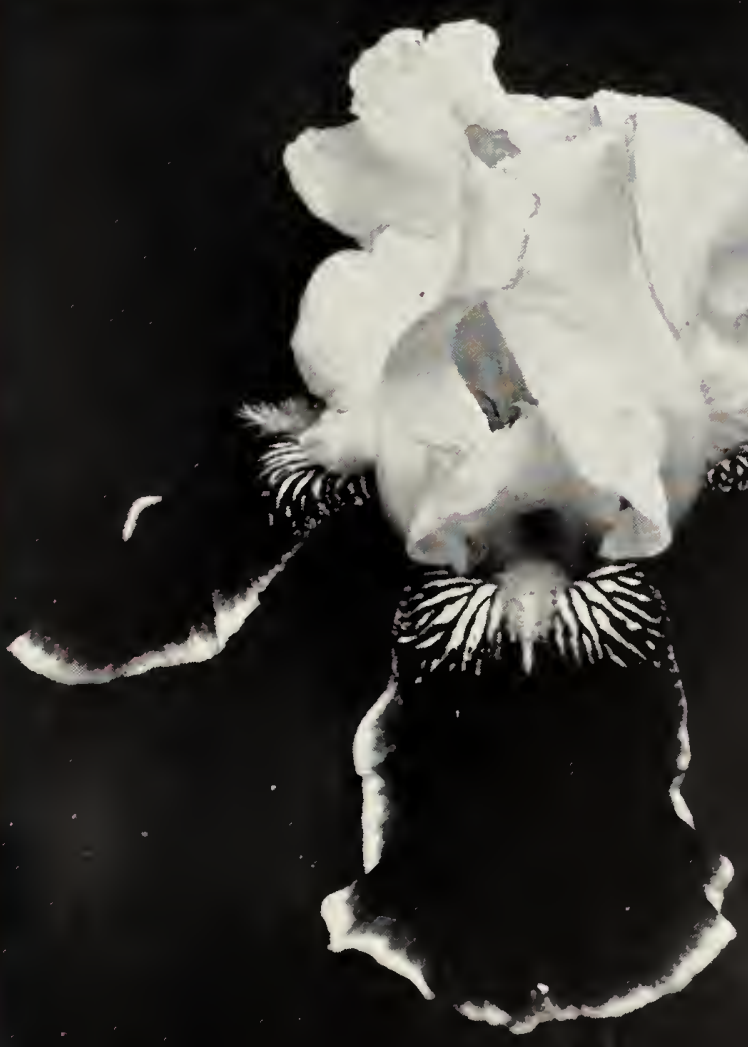

W $\bar{A} B \bar{A} \mathrm{SH}$ 


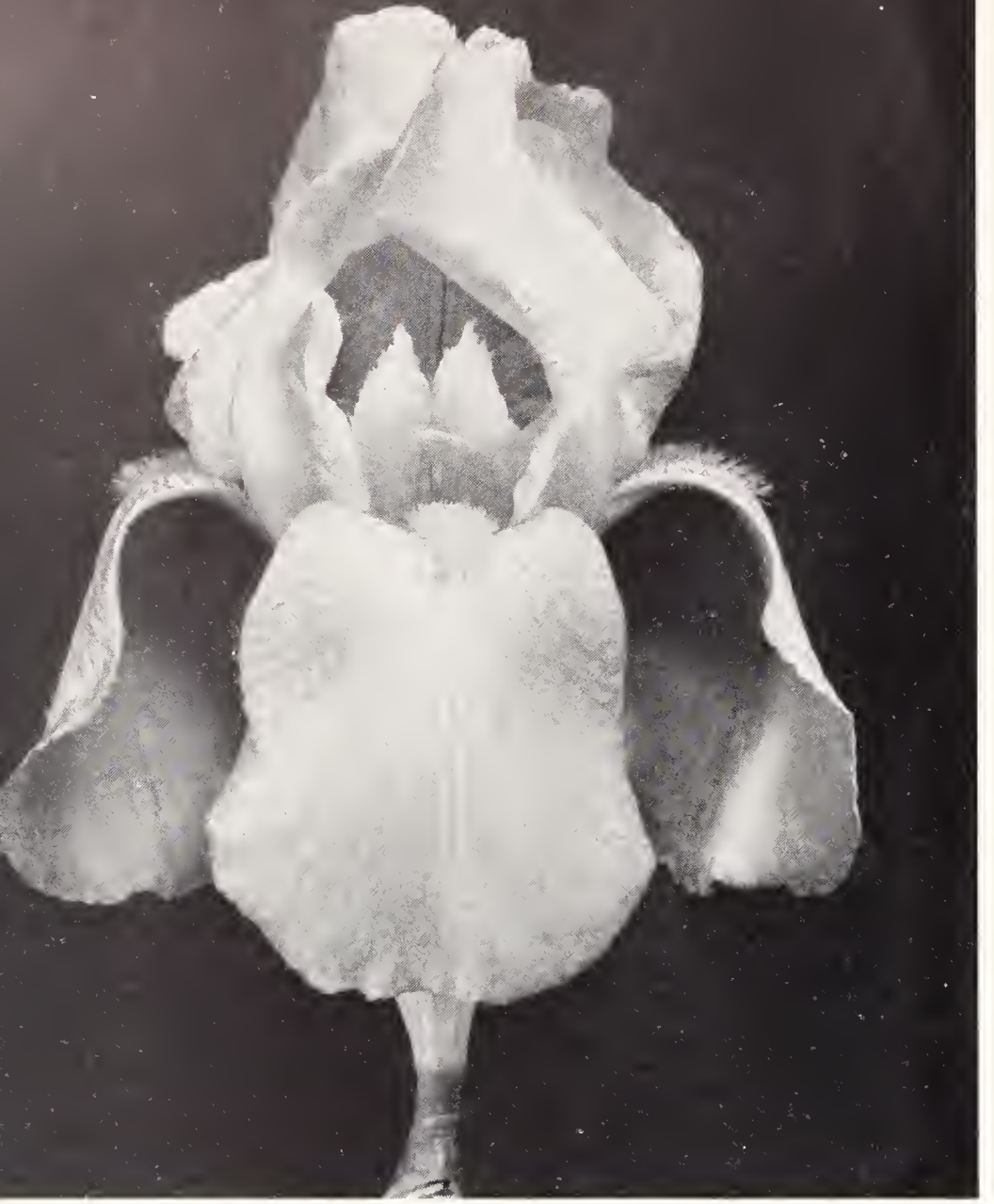

GOLDEN SLIPPERS

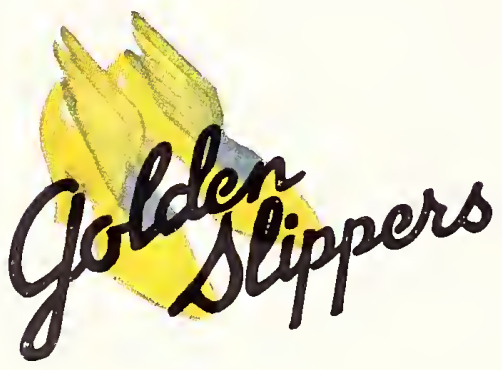

"Because it is so neat" - pure golden yellow, including the beard. A perfectly fashioned flower of medium size and height, with a mass of bloom and many branches. The tendency among breeders has been toward giant size and great height, but GOLDEN SLIPPERS is a garden flower, born to spill its myriads of clean cut daffodil yellow blossoms about in rank profusion. Increases rapidly.

Each $\$ 3.00 ; 3$ for $\$ 8.00$

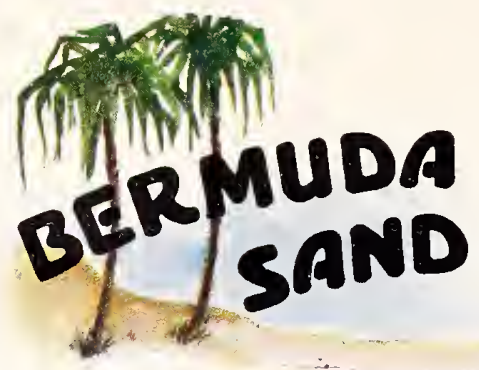

The formous seedling No. 36-71 from David Hall, and about which so much has been said and written. Some call it a glorified and gigantic more colorful Jean Cayeux, with both standards and falls heavily ruffled. General effect is a light coffee-tan with a glint of gold. It towers over Jean Cayeux in stature, does not fade, and is a rapid increaser and free bloomer. The color is difficult to describe, since it is not at all dull, but very bright and lively.

Each $\$ 15.00$

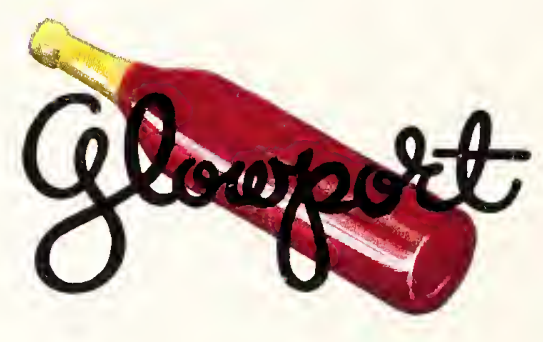

Discovered last spring among the seedlings of Mr. DeForest. A positive self of rich wine red, without the purple influence and almost devoid of haft markings, the beard bronze-yellow. The owner valued this most highly and had accumulated several splendid clumps. We promptly bought the entire stock and now pass on to you this most excellent ruby red iris at a fraction of its potential introductory value. Tall, well branched, does not fade in hottest sun.

Each $\$ 3.00 ; 3$ for $\$ 8.00$ 


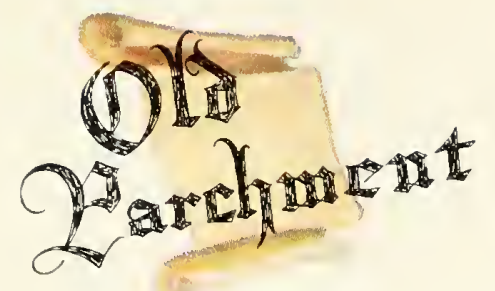

Creamy white with a golden buff overlay, a most unusual color break and a distinctly beautiful iris. Standards are domed and closed, falls flaring and rather tailored in appearance. The fine lines showing in the photograph are a bit misleading, for the flower is actually a self, unmarred by veinings of any other color. Three feet tall, low branched, a very fine grower. This novelty is further indication of the great versatility in Dr. Kleinsorge's iris breeding.

Each $\$ 15.00$

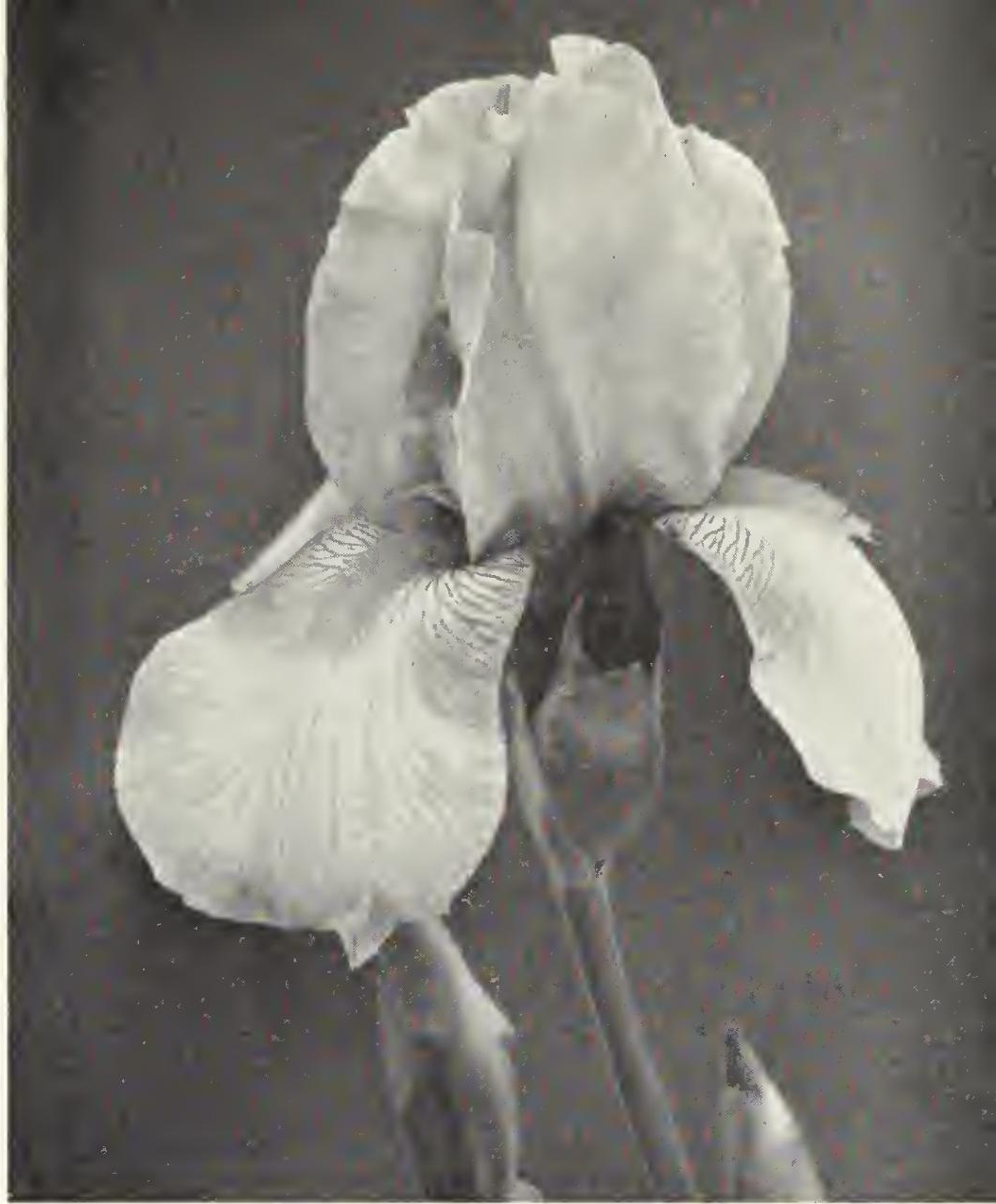

OLD PARCHMENT

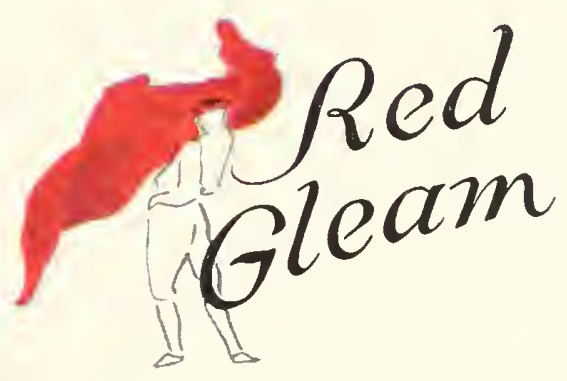

Years of painstaking work in hybridizing by Mr. Lapham have brought forth several of our finest reds and pinks. Now comes this newest and reddest of all reds, a color so startling and so vivid that critics declare, "It is almost scarlet!" Standards are of about the same intensity of color as the falls, but the latter are very velvety in texture and thus appear slightly darker. About the size and shape of Garden Magic. Height 36 inches. Very few plants. Each $\$ 25.00$ 


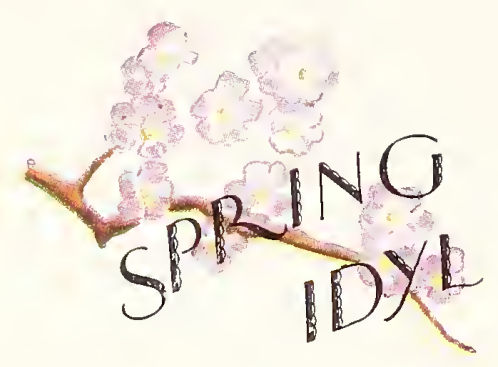

Noted for its daintiness, both in form and in color. A milk white, shading into orchid pink at the top of the standards and the bottom of the falls, with lemon beard. Tall wiry stems, the delicate blossoms amply spaced, give promise of great favor as a cut flower in addition to its special landscape value. An apple blossom effect, light and ciry. Very limited stock.

Each $\$ 10.00$

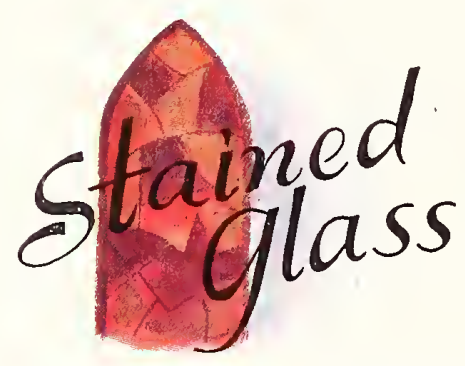

A copper red self, one of the most brilliant iris we have ever seen when viewed with the sun behind it. In such a light it resembles nothing quite so much as stained glass . . . rich, glowing, almost aflame! Make no mistake, this is not a red iris, but a solid copper of a reddish tone, the same all over except for the bronze yellow beard. Shown in the Chicago exhibit in 1938, it was given the AIS award of Highly Commended. It is the second iris so honored to be introduced by us, Modiste having won the laurels the previous year.

Each $\$ 15.00$

\section{TOKEN}

Many qualified critics have seen this new iris and the usual pronouncement is "a glorified Mary Geddes". Carrying much of the same salmony-orange-brown blended effect of this well known variety, TOKEN is a far finer individual flower-larger, of better form, and with smoothly colored falls. Standards are old gold flushed rose, falls rosy brown-red, with very little haft venation. It does not fade and is a husky grower, 38 inches tall, with blooms having a 7-inch spread. 


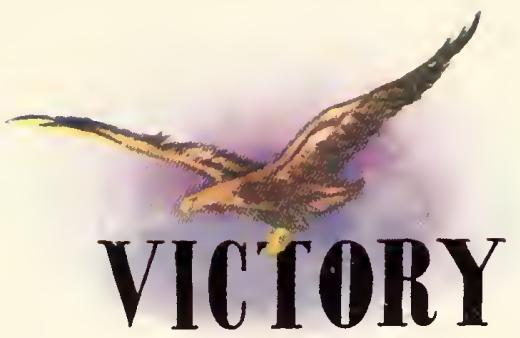

A striking violet purple of great size and excellent form on 44-inch very strong stems; branching and placement good. A richly colored self, with inconspicuous bluish beard. Standards are domed and the widely flaring falls are entirely devoid of haft markings. The originator says that this iris is very much admired by men.

Each $\$ 10.00$

\section{A NEW IRIS MOVIE IN COLOR}

Now you may enjoy your favorite flower in natural color during those long winter evenings, or renew their association any other season of the year when the actual flowers have long since passed.

We announce the release of a complete new film showing every phase of iris growing . . . our gardens in the height of bloom, masses of flowers in the extensive display gardens, acres of them in the nursery rows... scores of individual specimens, the newest and rarest, seedlings not even as yet on the market.

Have your garden club contact us now for bookings for the coming season. Full details sent upon request.

\section{AND HERE IS}

\section{SOMETHING FREE:}

A 24-page booklet, "LET'S TALK ABOUT IRIS", crammed full of information about iris growing, is yours for the asking. It was sent to all customers of record last year. If you do not now have a copy please ask for it. 
One of the very few perennials which knows no bounds o climate or geography.... we have shipped them to Alask and to New Zealand, and they grow and bloom lustily $i$ both places and in a thousand intermediate spots both her and abroad. North and South, in every state, Cooley's Irist

JAMES BAIRD FARM, NEW YORK, at the height of the iris season. Most of these plants came originally from Cooley's Gardens, 3000 miles away.

Duarfs, Intermediates and Fall Bloomers on pages 40 and 41.

ALINE

Each $\$ 2.00$

A truly lovely clean pure blue, large in size, on tall stems. This iris possesses an unusual enamel-like lustre which sets it apart from all other blues. Stock is scarce, hence it would be wise to order early.

\section{ALLIES}

Each 25c; 3 for $50 \mathrm{c}$

A French autumn flowering iris that has the habit of flowering intermittently throughout the summer as well as in spring and fall. Color is a combination of red-brown and fawn, a bit on the order of Dauntless. Rhizomes usually small but the flowers are of large size and the plants free blooming.

\section{ALLUWE}

Each 35c

A new type variegata blend from Hans Sass. Standards of yellow with a peachy suffusion, falls very long, of a ruddy tone shading into gold at the edges. Extra late, very tall.

\section{ALTA CALIFORNIĀ}

Each $30 \mathrm{c} ; 3$ for $75 c$

Standards clear yellow, falls deep yellow, faintly bronzed. One of the tallest of all irises, very popular among the new yellows, a reliable performer in Minnesota as well as New England and California. The large blossoms are of firm smooth texture, produced on splendid stems. Shown in color on page 39.

\section{AMENTI}

Each $\$ 1.00$

A Sass introduction of 1936. Grayish vinaceous standards, light mauve falls, pale yellow beard. This is a lovely pastel described by one admirer as a different Pres. Pilkington. The flowers are large, on finely branched stalks.

AMIGO roduction flower of similar type, with light lavender standards and very deep hyacinth violet falls, edged the color of the standards and margined white. Of Dominion form and pansy-like texture.

\section{AMITOLA}

Each $\$ 2.00$

Another Sass variety of 1937, something along the lines of Rameses in coloring, but coming from the originators of that Dykes Medal winner it can be relied upon to be a real and distinct novelty.
ANAKIM

Each $\$ 1.50 ; 3$ for $\$ 3.50$

Gigantic lavender, so outstanding in its color class as to defy all predecessors. Despite its colossal size, the flowers are graceful in effect, well carried on stems over four feet tall. The extremely broad falls are a noticeable feature. One of the parents of the new Wm. Mohr seedling, Ormohr.

\section{ANGELUS}

Each $\$ 10.00$

A new pink blend, size and shape of Depute Nomblot, of which it is a seedling. In color it is a bright light pink, with slight lavender iridescence just below the lemon beard. Throughout the center of the flower there is a delicate infusion of lemon yellow. Because of its size, heavy texture, and broad falls, it ranks as one of the very best of recent pink introductions. Produced in Wisconsin, its hardiness is beyond question. Height about three feet.

\section{ANITRA}

Each $\$ 5.00$

Beautiful shapely pale blue, color of the old variety Celeste, but of great size and splendid form. This is quite likely the finest blue iris ever originated by the Sass Brothers. Shown on page 7.

\section{ANNDELIA}

Each 20c; 3 for $50 c$

One of the last to bloom, a dainty pink plicata that produces a lavish amount of ruffled blossoms. Seldom offered. Rather low growing habit.

\section{ANNE MARIE CAYEUX}

Each $35 \mathrm{c} ; 3$ for $90 \mathrm{c}$

The smooth, soft tones of this iris are indescribable. The introducer says "a blending of the sky's colors at sunset and those of a pigeon's throat." The flowers are very large, of a thick and leathery substance. The whole effect is wonderfully beautifulsoft rosy heliotrope blended with grayish amber, beard orange.

\section{APRICOT}

Each $\$ 8.00$

A seedling of Far West, a solidly colored golden apricot self. The individual flowers are of medium to large size, with a slight fluting and ruffling in both standards and falls. Height about 3 feet. A Kleinsorge origination which we introduced last year and which is especially desirable because of its beauty at close range, when seen across the garden, or under artificial light indoors. Stock very limited this year. Shown on page 14. 
tre known ard cultirated, and beconte ever more popular ach succepding year. You, too, if you live in a spot where I garden can be grown, may hare complete confidence that tock bought from us will arrice in perfect condition, and, cilh reasonable care, grow and thrire and bloom to your ntire satisfaction.

\section{AT DAWNING} Appropriately named huge flower of arbutus pink
and brilliant rose, light yellow at the throat. There is a pearly suffusion in the standards. Stalks are very strong and hold the flowers well aloft on excellent branches.

\section{AUTUMN FROST}

Each $\$ 2.00: 3$ for $\$ 5.00$

A large flowered pure white, with golden haft and beard. A fall bloomer.

\section{AVONDALE}

Each $\$ 1.50: 3$ for $\$ 4.00$

Very large flower of subdued shades of copper, bronze and violet, beautifully blended. A reddish bronze effect in the garden, with very brilliant golden beard. Height 3 feet. Awarded an H. M. by the iris society in 1936.

\section{AZTEC COPPER}

Each $\$ 25.00$

Something entirely different in color, offered among this season's new ones. See page 5.

\section{BALLET GIRL}

Each $\$ 2.00$; 3 for $\$ 5.00$

Pure blush pink, soft and daintily colored, with large rounded flaring falls. Its daintiness and grace are indeed suggestive of a dancing girl. Above average size in the pink class, this clearly colored introduction from H. P. Sass and Robert Schreiner is bound to win popularity on account of its exquisite coloring and unusual charm.

\section{BEOWULF}

Each $\$ 3.00$; 3 for $\$ 8.00$

True maroon red, carrying neither the usual purple nor the oftimes coppery tone peculiar to red iris. Of full Dominion velvetiness, with standards and falls both carrying the uniform deep maroon color. A seedling of Grace Sturtevant, produced by Robert Schreiner and introduced in 1936. Large, early blooming, well branched.

\section{BERMUDA SAND}

Each $\$ 15.00$

Lovely sand-tan, or golden sand. A gigantic flower listed among this years introductions on page 8.

\section{BLACKAMOOR}

Each $40 \mathrm{c} ; 3$ for $\$ 1.00$

Dusky dark purple, with a metallic sheen and blue beard. The great flowers are very long in appearance, and the odd lustre gives them a certain individuality seen in no other sort. Free blooming with purple tinged foliage Very fine.

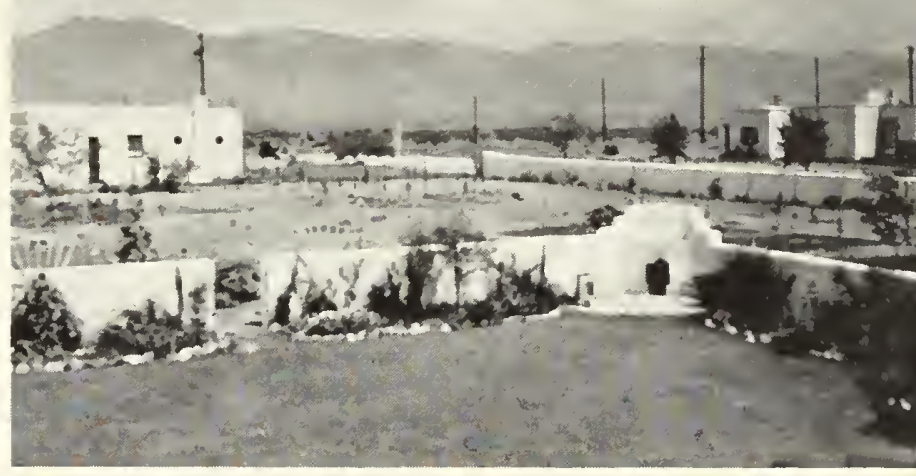

Circumstances having made necessary a change of residence to Tucson, Arizona, Mr. Baird moved the irises shown opposite to this new home. They now adorn the grounds equally as well as they did in New York.

\section{BLACK WINGS}

Each $35 \mathrm{c} ; 3$ for $75=$

Those who have been looking for a black iris will find that the quest almost ends here. The actual color is midnight blue, with a frosty lustre on the velvety falls. A big flower, easily grown, and one of the most popular varieties in commerce. Runner up for Dykes Medal, 1935.

\section{BLUE DANUBE}

Each $\$ 5.00$

An English introduction, a rich derp blue self. Said to approach the coloring of an anchusc. with a blue tipped beard. We have not seen it but will flower it here this spring.

\section{BLUE PETER}

Each $\$ 2.50$

Highly praised very deep blue, extra brilliant. Tall and stately, reaching 40 inches, with very large well placed blooms. Limited stock.

\section{BLUE SPIRE}

Exch $\$ 3.50$

As the name indicates, a very tall and classically beautiful flower. The newest blue from Milliken, who has put out such things as Sierra Blue, Shining Waters, Pale Moonlight and Blue Peter. He regards this as perfection itself.

\section{BLUE TFIUMPH}

Each $\$ 1.50$

Very pale blue, of soft even tone but heavy substance. Huge stalks, carrying from 12 to 15 flowers, widely set apart. Produced by Mr. Grinter, who gave us Garden Magic and Missouri.

\section{BROWN BETTY}

Each $\$ 1.00$

Blended shades of cinnamon and other browns, with some copper and lavender intermingled. Very distinct and beautiful in its native California, but inclined to lush growth and a bit erratic here in the moist Northwest.

\section{BRUNHILDE}

Each $\$ 2.00$

Very dark uniform violet blue self, including an unusual blue beard. A most regal iris that will be particularly welcome because of its color intensity and unusually smooth finish. The flowers are of perfect flaring form, the stalks low and widely branched. carrying up to 20 buds. Beautiful under artificial light. A Carl Salbach introduction of 1934.

\section{BUCKSKIN}

Each $\$ 10.00$

No iris was ever more appropriately named. A big husky new one; see page 5. 
Does not fade, and shows no paling in standards, falls, or beard. Said one iris enthusiast, gazing upon one of its full blown golden blooms for a full minute, "It isn't so. There is no such iris". Runner-up for Dykes Medal in 1937.

\section{CASQUE D'OR}

Each $\$ 15.00$

Deep old gold standards, considerably ruffled, with greenish mid-ribs. Falls are richest blackish maroon or oxblood, depending upon whether seen with the sunlight on or through the flower. Height 34 to 36 inches. This slightly resembles El Tovar, but is brighter and even more striking. .

\section{CHARM}

Each $\$ 4.00$

Bright strawberry red, with very little reticulation at the haft. Of large size but medium height, from hardy parentage.

\section{CHEERIO}

Each $\$ 2.00$

A popular variety of recent introduction in the bright red class, with tan standards and flaming red falls.

\section{CHINA MAID}

Each $\$ 5.00 ; 3$ for $\$ 12.00$

Here we are again confronted with the almost impossible task of describing an indescribable iris! This is in shades of pink, golden copper, and lilac, smoothly blended together. It was one of the loveliest new ones we viewed last season, with large size and fine form adding to its high quality. It is truly different.

\section{CHOSEN}

Each $\$ 15.00$

The great new yellow from Southern California. APRICOT

\section{BURNING BRONZE}

Each $\$ 1.50 ; 3$ for $\$ 4.00$

A dark but blazing metallic red, a flower of great size, and one of the superfine seedlings grown by America's foremost hybridist, Dr. Ayres. This spectacular flower created a sensation when shown at the AIS meeting in Freeport in 1933, and some critics pronounced it the finest red iris in existence. It differs from most others in its bronzy finish. H. M. AIS 1933. See page 35.

\section{CAFE AU LAIT}

Each $\$ 17.50$

A lovely blend, soft creamy tan, with orange and gold shading. Finest seedling from the late Sam Graham, of Rome, Georgia, it was introduced last year by Quality Gardens and highly regarded by all critics. Large flowers, stems reaching three and onehalf feet in height, hardy, and a fine increaser.

\section{CALLUTTA}

Each $\$ 6.00$

A very tall and imposing flower in soft cocoabrown tones, entirely overlaid with a bluish veil. Of bold growing habit, widely branched, carrying more than a dozen blooms per stalk. Height four feet. This is one of a series of blends grown by Dr. Kleinsorge selected for introduction in 1938.

\section{CALIFORNIA GOLD}

Each $\$ 2.00 ; 3$ for $\$ 5.00$

The deepest large flowered yellow, being a seedling of Grace Sturtevant and unquestionably hardy.
It is of tremendous size, solidly colored throughout, a rather metallic shade of yellow with odd greenish cast. It is not a dirty green, however, and we mention this greenish yellow simply to set it apart from the deeper golden yellows. It is a flower of pure color, even the beard being the same uniform shade.

\section{CHRIST ABEL}

Each $\$ 7.00$

Red ... and it will not disappoint the most exacting critic. Introduced without glamour, Christabel has become increasingly popular with wider distribution. For sheer brilliance we rank it second only to the new Red Gleam from the same originator. Glorious in a garden clump, almost a self, of large size, over three feet tall.

\section{CITY OF LINCOLN}

Each $\$ 20.00$

Brightest, largest and surely the finest of all variegatas. Clear golden yellow standards, broad fiery red falls, startling in their contrast. Of bold habit, one of the triumphs from Hans Sass.

\section{COPPER LUSTRE}

Each $\$ 3.00$; 3 for $\$ 8.00$

Dykes Medal, 1938. Absolutely unique, a magnificent iris from the hand of Dr. Kirkland, who gave us Desert Gold, Black Wings, and a number of very recent novelties certain to make a fine impression on the iris growing public. Copper Lustre positively glows in its bright copper, gold, and pinkish tan blendings. It is a huge flower, with lush foliage, and in the garden of its originator was the center of attraction and comment when the American Iris Society met in Nashville. H. M. AIS 1935, A. M. 1937. See page 15. 


\section{COPPER \\ LUSTRE}

(Kirkland, 1934)

\section{DYKES MEDAL}

\section{8}

True to prediction, this great iris, often referred to as "the iris of the Century", came through to win the highest award possible last season.

Entirely different from all others, its great popularity has resulted not only from the odd and beautiful copper tone of its flowers, but also from the fact that it seems to perform well in all sections of the country. Where it is established on two year plants the flowers are of great size. on excellently branched stalks, and the foliage is healthy and vigorous. Hardiness is proven without any question.

The picture alongside is but a fair likeness - it does not convey the brilliance nor the coppery sheen which distinguish the actual flower.

Each $\$ 3.00$ Three for $\$ 8.00$ 


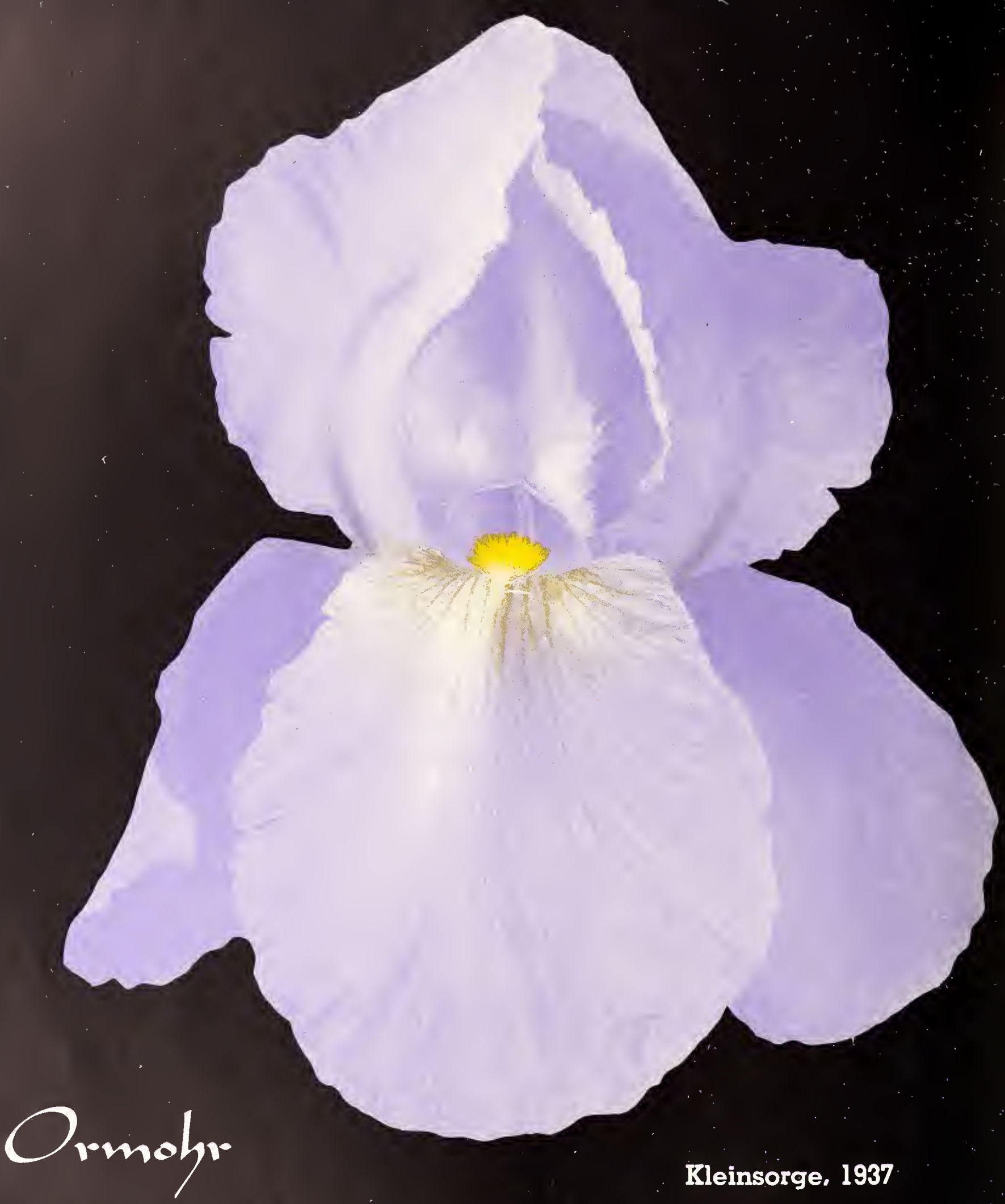

A Wm. Mohr seedling that stands almost $\mathbf{4 0}$ inches tall, with giant. flowers of a uniform gray-lavender veined violet. There is a faint rosy glow over the entire blossom. ORMOHK is not only the result of a rare and difficult cross, but it contains a quarter Bruno blood and is itself an abundant producer of seed when crossed. "Perhaps the boldest iris grown," says a nationally known critic. A rugged grower, well branched.

Each $\$ 20.00$ 

A blend of pink and red that approaches raspberry color in effect, with a dazzling note added in the bright golden beard. With this fine variety Dr. Ayres has scored honors again, for Coralie was awarded an H. M. by the AIS in 1932 and in 1933 was given the Dykes Medal. Such recognition stamps it as a certain leader for many seasons to come.

\section{CORINTHE}

Each $\$ 5.00$

A new French introduction from Cayeux that was awarded a special Certificate of Merit in Paris in 1934. The flowers are of immense size and beautiful coloring, with broad arching standards of rich silky bishops violet. The falls are broad and spreading, of richest velvety bishop's violet. A strong grower, reaching four feet in height. Very few rhizomes.

\section{CORONET}

Each $\$ 22.50$

Soft rose-beige with a golden tone, a new color and one of the leading novelties from Quality Gardens in 1938. Produced by David Hall, the man who originated the iris on our cover and four of our new offerings for this year. Coronet is tall, widely branched, with fine rounded flowers of large size.

\section{CREOLE BELLE}

Each $\$ 1.50$

A very dark blue purple, with odd brownish stain about the hafts. Individual in effect, of large size and excellent habits. One of the recent things from Col. Nicholls, awarded an H. M. in 1936.

\section{CRYSTAL BEAUTY}

Each $\$ 1.00$

A new white from the Sass Brothers, said by some to be the cleanest white yet produced. It has been highly praised by critics in the Iris Bulletins. Height 40 inches.

\section{CYRUS THE GREAT}

Each 75c

A great, flaring, dusky rich purple self. Huge in size, very heavy flowering. From Chancellor Kirkland, producer of Copper Lustre.

\section{DAUNTLESS}

Each 25c; 3 for $50 \mathrm{c}$

Probably the most popular and widely known of all so-called red irises. Although we now have several newer introductions that surpass it, none the less Dauntless remains near the top, and there has never been sufficient stock to supply the demand. The blooms are of great size, on tall heavy stems, and last over a long season. The coloring is rich velvety red, with very little of the blue or purple undertone. A former Dykes medal winner.

\section{DEPUTE NOMBLOT}

Each 25c; 3 for $50 c$

One of the world's greatest irises, a French introduction that has proven extremely popular everywhere. Standards light glowing rosy-purple, overlaid bronzy gold. Falls very wide, spreading, purplish garnet-red shading to lighter rosy bronze at the edge. Deep orange beard. Over four feet tall, especially well branched. A Dykes Medal winner in France.
Here is a "brushed" variegata, a flower quite apart from others of this class, creating a red-orange tone in the garden. As exciting and gay as a gypsy carnival, says the introducer. Standards are very deep yellow, falls the same heavily brushed chestnut red.

\section{DESERT GOLD}

Each 25c; 3 for $50 \mathrm{c}$

Among the earliest of the tall bearded group. An extremely large, fine formed, smooth clear yellow. Standards are nicely domed, pure light yellow. Falls are extra broad, pure yellow with very rich yellow beard. It certainly is deserving of a position among the best new introductions. Plant a clump in front of several clumps of Santa Barbara-they bloom together, and what a picture! H. M. AIS 1931; A. M. 1932.

\section{DESTINY}

Each $\$ 3.50$

From New Zealand. A great heavy flower of deepest blackish bronzy purple, with rich golden beard. If you think the ultimate has been reached in such colors, wait until you see this one and Directeur Pinelle . . . they are both real surprises!

\section{DIRECTEUR PINELLE}

Each $\$ 2.50$

Among the arrivals from France in recent years this ranks near the top. Few iris are of greater size, with such splendid form and branching habit. The color is richest maroon purple, with bronzy undertone. Newly opened blossoms are almost black.

\section{DOGROSE}

Each $30 \mathrm{c} ; 3$ for $75 \mathrm{c}$

A very beautiful, superb pink iris, with very large oval shaped flowers in a uniform shade of soft rosepink, with deep gold beard. The stalks are almost shoulder high, and it is a profuse bloomer. This variety will show up to best advantage after it has become established a full year. Winner of a silver medal in England. Small rhizomes. Shown in color on page 23 .

\section{DORE}

Each $\$ 1.50$

A yellow and cream bi-color, the standards being light yellow and the falls creamy white. It is the only color combination of this kind in our list. Large flowers on 36-inch stalks.

\section{E. B. WILLIAMSON}

Each $\$ 15.00$

Glowing coppery red blend, a deeper and redder effect than Rosy Wings. The originator, Paul Cook, of Bluffton, Indiana, has raised thousands of seedlings over a period of many years, and this is his first introduction. We saw it there last season and promptly bought stock. Not to be confused with either the reds or the coppers, it stands in a special niche all its own. Large flowers of silky texture, fragrant, on 3foot stems. 


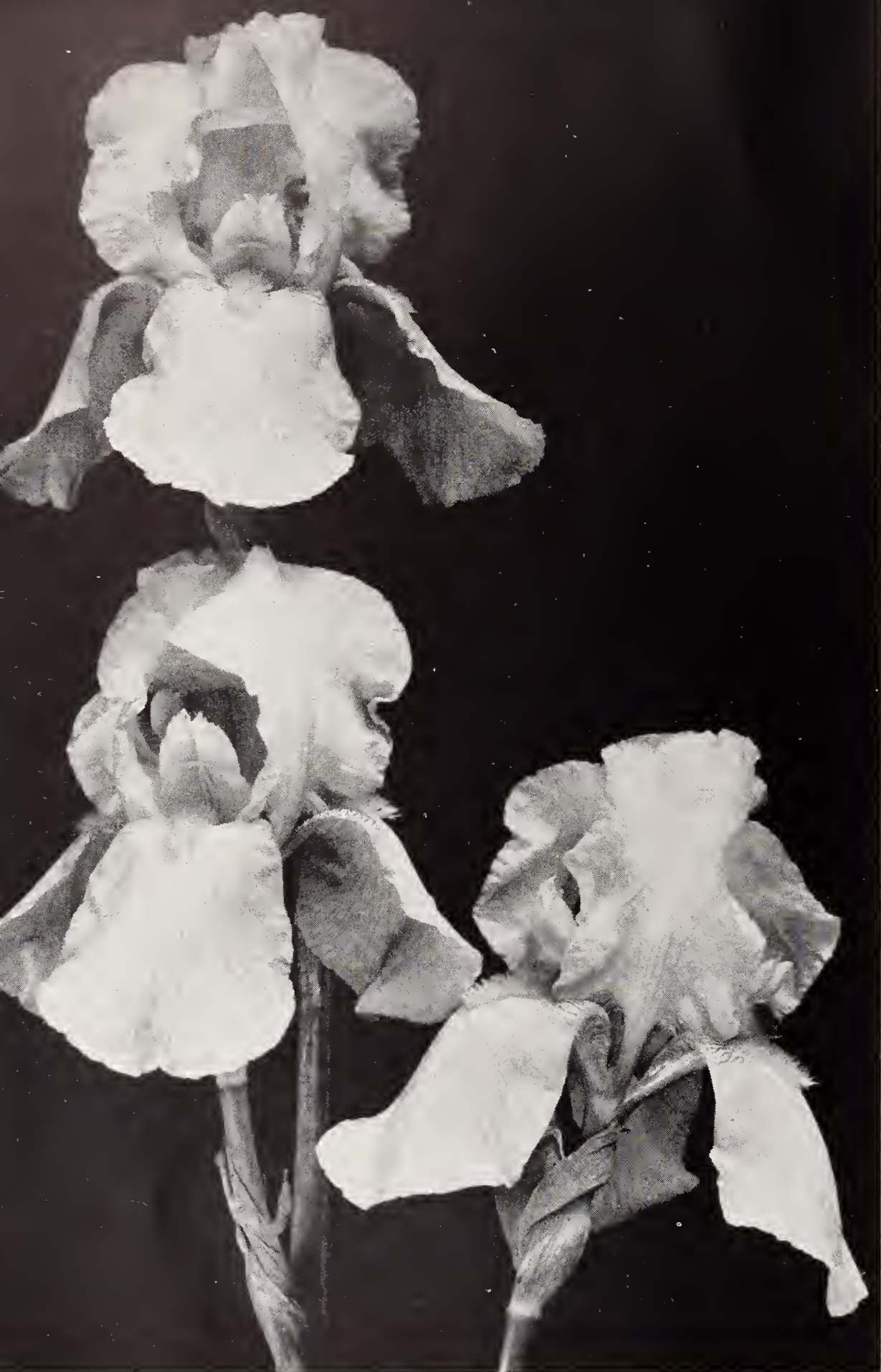

GLORIOLE

\section{NOVELTY Collection 8 for $\$ 25$}

You Select Them - Two from the first set, two from the second and four from the third.

\section{ANY TWO}

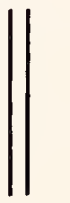
Far West
Golden Treasure
Lighthouse
Rosy Wings

\section{ANY TWO}

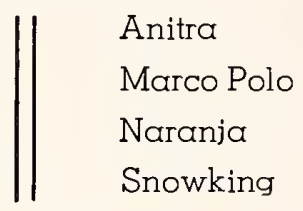

\section{ANY FOUR}

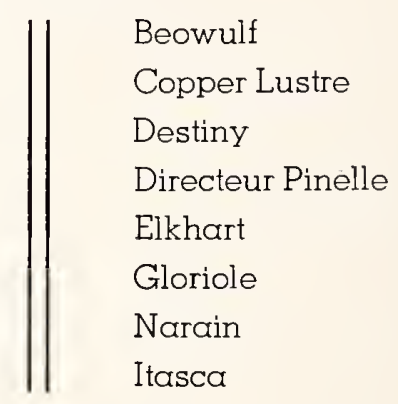

Kindly observe the conditions of this offer. Do not select more than two from the first set, two from the second set, nor more than four from the last set. Please do not request us to accept an order for less than eight nor to substitute varieties not in the list.

\section{EASTER MORN}

Each 50c; 3 for $\$ 1.25$

Remindful of all that is pure, like the candles and lilies at an Easter service. A creamier and heavier white than Purissima, with a rich golden center, flaunted on giant stalks that spring from broad sword-like foliage of vivid green. A flowering specimen in one's garden is a sanctuary for all visitors.

\section{EL CAPITAN}

Each 25c; 3 for 50c

Here is one of the best and most popular irises ever originated, a gigantic light manganese violet bicolor, a frequent winner at the shows, and a real stunner in the garden.

\section{ELKHART}

Each $\$ 4.00$

Deep chestnut red, introduced in 1937. This iris appears red in certain lights, brown in others, with a vivid beard. It is large in size, rounded in shape, with well branched stems. A seedling of Ethel Peckham crossed with King Tut, produced by Mr. Lapham, of Elkhart, Indiana.

\section{ELLA WINCHESTER}

Each $\$ 4.00$

Deep mahogany red self with very long velvety falls. Absence of haft markings give it great depth of color. 30-36 inches. 
A new outstanding pink, produced by E. G. Lapham, of Elkhart, Indiana, and introduced in 1933. A heavy flowering variety, it evoked the following comments in the AIS Bulletin for October, 1933: "The largest flower of any pink I have seen. A 'best seller' in my garden. A larger flower than Pink Satin." Deep pink in general effect, with lemon beard. Height 3 feet. See page 39.

\section{ETHIOP QUEEN}

Each $\$ 15.00$

We hear a lot about "black" irises; this is surely a near approach, with standards of deep blackish violet and falls practically coal black. The substance is extra heavy and velvety, with a glistening sheen. Medium in size, 30-36 inches tall, well branched. Schreiner's own seedling, introduced in 1938.

\section{EUPHONY}

Each 20c; 3 for $50 c$

The standards are mustard yellow, waved and fluted, stained with light brown at the tips. Falls are squarely held, mustard yellow, flushed with blue in the central portion and overlaid soft brown. This is a lovely and bright color harmony, and the great freedom of bloom of this variety makes it a heavy favorite. See color reproduction on page 23.

\section{EVELYN PULLAR}

Each $\$ 10.00$

A new departure in tall bearded iris, one which begins blooming in late fall and continues throughout the winter. Full account on page 40.

\section{FAIR ELAINE}

Each $\$ 25.00$

Selected by us as Salbach's finest new introduction last year. Yellows are now plentiful, but this one is distinct and beautiful in its own right. Standards are almost cream, the falls an emphatic brilliant yellow. The whole is enlivened by a vivid orange beard. A real color break and a lovely iris. Height 40 inches.

FAR WEST (Kleinsorge, 1936) Each $\$ 6.00 ; 3$ for $\$ 15.00$

Shown on page 19, a warm and mellow blend of salmon and golden sand, of coral and henna, with a soft glow at the heart. Originated in the West, and containing that multitude of tints seen in the western

EL TOVAR

Each $\$ 1.50$

A gorgeous variegata blend, in rich brown-yellow and blackish maroon, with a yellow glow at the heart. This iris is one of the foremost of all new introductions of the past three years, having been awarded an H. M. of the AIS in 1932 when first exhibited. Nothing like it. Height 3 feet.

\section{EROS}

Each $\$ 1.00 ; 3$ for $\$ 2.50$

Very tall salmon colored self, possibly the nearest to this color ideal that has ever been offered. The throat is lit with gold, giving it a brilliance and warmth especially telling in garden effect.

\section{ETHEL PECKHAM}

Each $\$ 1.25 ; 3$ for $\$ 3.00$

Large, perfectly formed flowers of a blazing reddish tone. This iris, placed on the market in 1932 , has enjoyed tremendous popularity. The color is extremely bright, nearly a uniform shade in standards and falls. It boasts every good point in growing habit, and in addition usually throws up occasional stalks throughout the summer and fall! sky at sundown. Of bold and sturdy growing habit, the big blooms are well spaced on fine stalks reaching 40 inches in height.

The likeness of this flower is achieved by a new process and we guarantee its absolute accuracy, although some reduction in size was necessary.

\section{FIEST A}

Each $\$ 6.00$

Sparkling copper standards, apricot-orange falls, a very gay affair! The large oval blooms are well held on 3-foot stalks. Here it seems a bit too lush in growth to flower consistently, so we do not recommend it for moist climates. In California and similar climatic sections it is excellent.

\section{FRIEDA MOHR}

Each 20c: 3 for 50c

Dependable anywhere, despite the fact that it was originated in California and contains tender blood, it is perfectly at home in Ohio, Minnesota, and New England, as well as in the moist climate of the Pacific Northwest. The color is a lively shade of violet-pink, standards slightly lighter than the falls. Its huge size and great height make it a leader in any color class. See color illustration on page 23. 


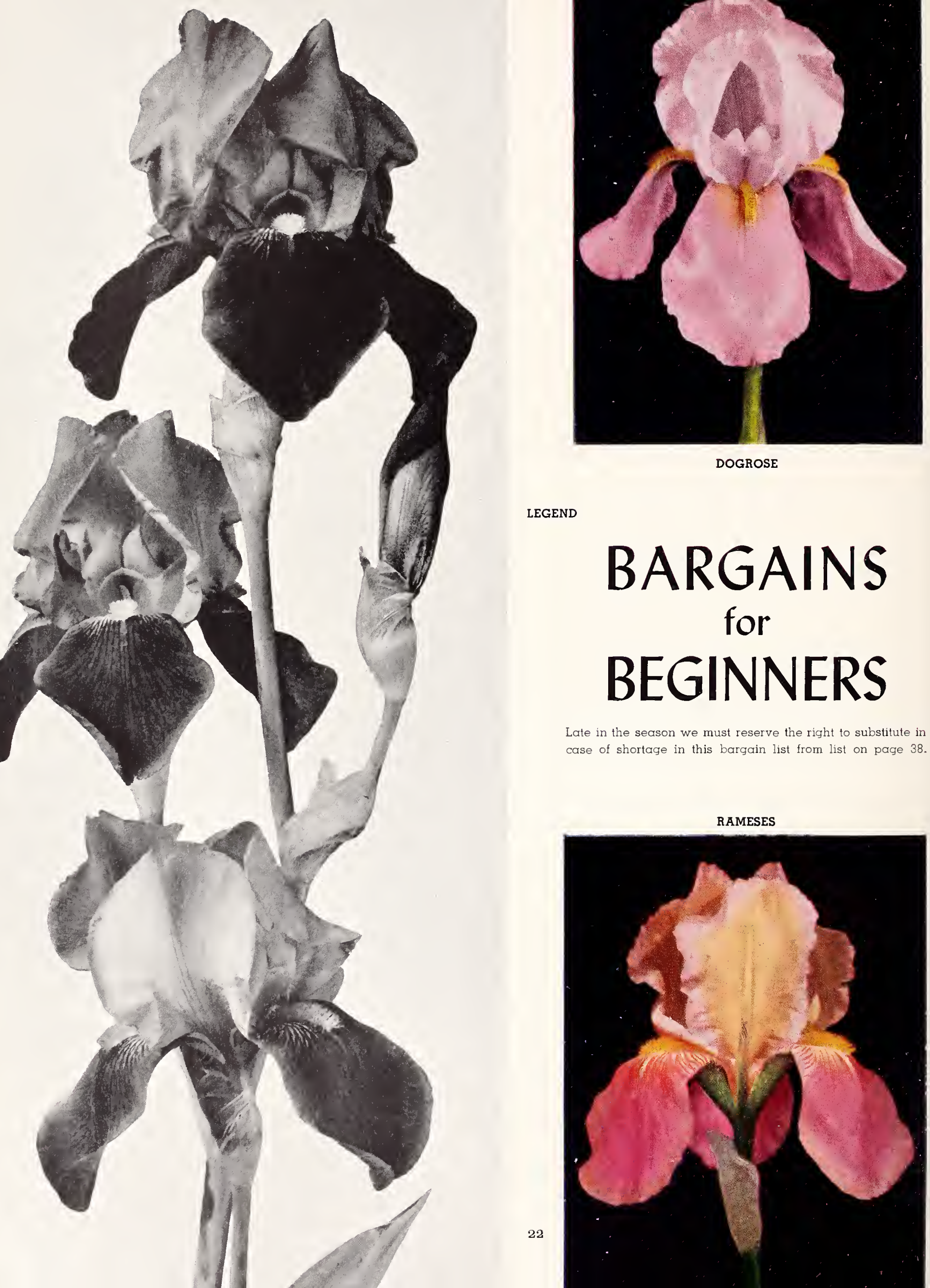




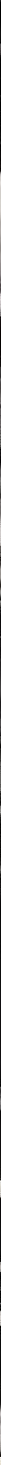

KALINGA

\section{GREAT LĀKES}

A new clear blue self, grown in Canada by Iyman Cousins, of London, Ontario, A broad, spreading, regal type of flower, with handsome foliage and finely branched four-foot stalks. Color is about the same shade as Shining Waters, slightly nearer to true blue, however. Standards are tightly closed, no veining at the haft, and the flowers hold their color remarkably well. Awarded the honor of Highly Commended last season. Pictured on page 6.

\section{GUDRUN}

Each $\$ 1.00$

Heavily textured enormous white, from the well known Mrs. Dykes in England. The flowers are very long, with falls that spread outward at the tips. Beard is brilliant orange. This is a warm, or creamy white, with a slight gold sprinkling over the entire bloom. A one-time winner of the Dykes Medal. See page 20.

\section{HAPPY DAYS}

Each \$2.00; 3 for $\$ 5.00$

A solid uniform bright yellow, in size as large as the giant El Capitan, and acclaimed by every iris critic who has seen it. Compared with California Gold, Happy Days is a brighter yellow, with a slight undertone of orange, as against the deep greenishgold of the former. They do not compete with each other, being entirely different and similar only in that they both are ultra modern extra fine yellows. H. M. AIS 1935

\section{IMPERIAL BLUSH}

Each 40 c; 3 for $\$ 1.00$

A new creamy pink, tall, with very large blossoms, of delightful perfume. The stems reach 40 inches in height. A Sass production, vigorous and very free flowering. This does not carry any of the yellow glow of most other pink toned irises.

\section{INDIGO BUNTING}

Each 50c

Something different in clear blue, a rather deep shade, nicely formed, with an odd brownish suffusion near the haft. Flowers are freely produced, making it excellent as a garden or landscape subject. Good blues are in keen demand and this is one of the best.

\section{ITASCA}

Each \$2.50; 3 for $\$ 6.00$

Raised by Dr. R. E. Kleinsorge, Silverton, Oregon. A positive self of the darkest, yet most vivid, deep amethyst. It carries no veining whatsoever, and the great depth of tone is intensified by a heavy brown beard, underlaid with blue. The texture is like silk, and the flowers are rounded in shape, with nicely branched stalks 30 to 36 inches high. See page 34 . 
JASMANIA

Each $\$ 8.00$

Picked by many critics in all sections of the country as the best yellow in commerce. It is tall, very large, beautifully formed, of heaviest substance. The color is about that of a ripe banana! Near the center is a faint suggestion of light brown, and a still fainter flush of pale blue in the center of the falls. Thus it cannot be termed a clear yellow, although it is almost so, and is actually the more beautiful for its blended additions. Truly one of the iris of the day, and one of Dr. Ayres' greatest achievements.

\section{JEAN CAYEUX}

Each 75c

Certainly one of the most beautiful irises we have ever flowered in our gardens. Likewise, it is one of the most unusual in color-a soft, smooth, light buff, described by some as "coffee colored" and by others as Havana-brown. The form is perfect, and the size is larger than average. It is splendidly branched, over three feet tall, and flowers over a long season.

\section{JEB STUART}

Each $\$ 2.00$

Deep blackish brown, with rich orange beard. A great improvement on Grace Sturtevant, being larger, taller, and of much better form. Awarded an A. M. by the American Iris Society in 1935. Limited stock.

\section{JELLOWAY}

Each $\$ 6.50$

A new and spectacular yellow iris, as deep in color as the famous Golden Hind, oval in form, with golden yellow beard. This variety has brought on much discussion, everyone agreeing that the color is unsurpassed. It was awarded the A. M. of the AIS last year.

\section{JERRY}

Each $50 \mathrm{c} ; 3$ for $\$ 1.25$

Raised by Mr. E. G. Lapham, Elkhart, Indiana. We take particular pleasure in being numbered among the joint introducers of this perfectly formed, extremely brilliant red iris. Mr. Lapham has a splendid reputation for quality in his previous introductions, and enthusiasts will find that Jerry is very close to the reddest thing ever turned out in an iris. Not only that, but the large rounded flowers are as near perfection as could be desired. Height three feet, rapid of increase, hardiness unquestioned. We recommend it whole-heartedly.

\section{JOYCETTE}

Each $85 \mathrm{c} ; 3$ for $\$ 2.00$

Red, that is, as red as any iris we have and with both standards and falls in identical tones. This is a fine grower, with tall sturdy stalks and extra large flowers. Some critics declare this better and redder than Ethel Peckham; they are somewhat similar, Joycette undoubtedly being the taller of the two. No doubt but that this ranks with the leading introductions to date. We have a wonderful stock of it.

\section{JUNALUSKA}

Each $\$ 2.00$; 3 for $\$ 5.00$

One of the finest novelties in commerce today, a unique blend of red, copper, and rose. A member of the trio of especially worthwhile things produced by the Chancellor of Vanderbilt University, Dr. J. H. Kirkland, the other two being Copper Lustre and At Dawning. This flower possesses tremendous garden value with its glowing copper-red effect, and leaves nothina to be desired in the way of size, height or form. Runner-up for Dykes Medal, 1938.
Huge cream self, outstanding not only as an exhibition spike, but as a garden specimen as well. The broad, spreading, ivory textured blooms generally come out in groups of three or four simultaneously, and each stem will carry from twelve to fifteen flowers, with perfect spacing. An offspring of Dolly Madison, its hardiness is beyond question. Four feet in height. Illustrated on pages 16 and 24. H. M. 1936.

\section{KHORASAN}

Each \$2.00: 3 for $\$ 5.00$

New blended variegata, with peculiar "auburn" tinted falls flushed violet. The standards are dull old gold. Petals are waved at the edges, very heavy in texture. A Sass introduction of 1937.

\section{K. V. AYRES}

Each $\$ 1.00$

Very pale coffee color, tinged lavender and cream. A huge soft blend with very tall stems and heavy foliage. This iris was named by Dr. Ayres in honor of his wife, a sure sign that he regarded it most highly.

\section{LADY PARAMOUNT}

Each $\$ 1.00 ; 3$ for $\$ 2.50$

The sensational new seedling of the famous variety W. R. Dykes. A really magnificent flower in clear primrose yellow, with firm silken texture. It is one of the most stupendous in size and foliage in our collection.

We have several reports of excellent success in Nebraska, Ohio, and New England, where this iris has been very well grown. Not nearly so deeply colored as either California Gold or Happy Days, it is nonetheless one of the most beautiful varieties we have ever flowered, and will take its place among the best.

\section{LA FERIA}

Each $\$ 4.00$

An odd French-grey self, with brownish stain near the haft. A subtle and lovely combination of colors, the flowers very large with wide hafts and flaring form. 40 inches.

\section{LEGEND}

Each 25c: 3 for $50 \mathrm{c}$

A huge flower of the Cardinal type; rich deep claret falls, seemingly of pure velvet, and standards of deep blue, slightly bronzed. The color combination is a bit like that in Sir Michael, although Legend is considerably darker all around. The flowers are enlivened by a heavy gold beard. Here is one of the largest and most majestic irises in commerce today, with every possible good point, and the price is reasonable for such a new introduction. From the Wareham collection in Cincinnati. One of Schreiner's "ICO Super-Iris". Shown on page 22.

\section{LIGHTHOUSE}

Each $\$ 5.00$; 3 for $\$ 12.00$

A very bright rose blend, of bold growing habit with enormous blossoms. In effect an old rose self with a most brilliant center of yellow and fiery gold. Among the hundreds of new iris seen on our trip in 1937 this struck us as among the outstanding halfdozen. A California production, but being a seedling of Helios x Rameses its hardiness is assured. It was particularly fine in New England. 


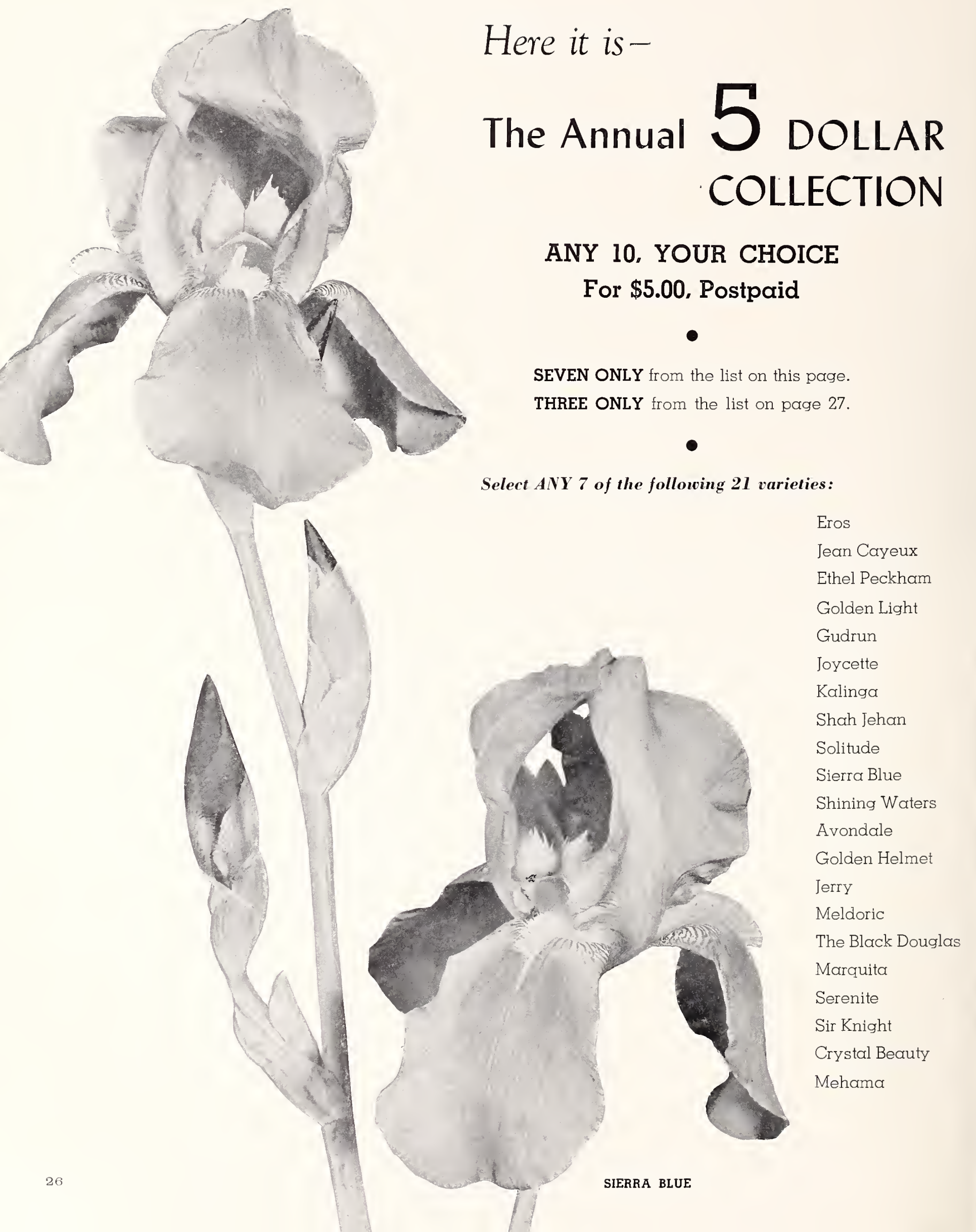




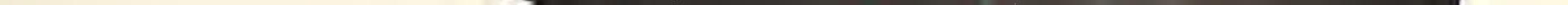




\section{LILAMANI}

Each $\$ 7.50$

Silky new blue-black from Jacob Sass, taller, larger and darker than Black Wings, say the reports reaching us. We have not bloomed it at the time our catalog is written.

\section{LILY PONS}

Each $\$ 2.50$

Tall, well branched, flaring pinkish blend. The flowers are large, rather narrow at the haft, but of heavy substance and well formed.

\section{LODEST ĀR}

Each 25c; 3 for $50 c$

One of the last to flower, this bright combination of glittering yellow standards and very dark brownish falls is a real "high light" in any garden. Flowers are of perfect formation, lavishly produced. Height about two and a half feet. Very small rhizomes always.

\section{LOUVOIS}

Each $\$ 12.50$

Brown, deep rich and velvety, like the lustrous fur of an animal. This new French sort was one of the outstanding surprises last year. Stock is very limited in this country and when collectors of novelty iris see it in bloom a shortage of plants is almost certain to follow. Standards are a decided brown tone, the falls exceedingly dark blackish-brown, shading out slightly at the edges to match the lighter color of the standards. The finest and most unique iris from Cayeux in several seasons.

\section{MAGENT A}

Each 20c: 3 for 50c

Very deep amethyst-violet, a shade not comparable to any other iris. Very free blooming, with flowers better than average size. This is another variety which makes a grand showing on a two-year clump, and especially when planted adjacent to pink or yellow.

\section{MARCO POLO}

Each \$4.00; 3 for $\$ 10.00$

For several years we have heard of the spectacular red seedlings grown by Robert Schreiner in St. Paul. In 1936 he introduced two of them-Marco Polo and Beowulf. This one is the more brilliant red of the two, with lustrous rose standards and vivid crimson velvety red falls. There is no venation on the haft and a bright orange beard contributes a touch of high color.

\section{MARGARET ROWE}

Each $\$ 3.50$

A deep old rose self, set off by a brilliant gold beard and haft. This fine iris was grown by Dr. Ayres of Cincinnati and introduced by Mrs. Emigholz of the same city.

\section{MARQUITA}

Each $\$ 1.00$

A well named iris in brilliant ivory yellow, with ochraceous maroon veinings on the falls. The standards are ivory deepening to sulphur at the base, and so large that they constitute the major portion of the flower. Falls are of the same color, but entirely lined maroon. This very late novelty was one of the two or three most popular things among our visitors last season.

\section{MARY GEDDES}

Each 50c; 3 for $\$ 1.00$

In the forefront of American introductions during the past two or three seasons, and for that matter, one of the finest and most distinct irises of all time. The color is light ochraceous salmon, the falls stained deeper. In our garden it has always exhibited fourway branching habit, and is one of our longest lasting varieties. Very little stock available anywhere in the country. Awarded an A. M. at Wisley, England, in 1933. Dykes Medal, 1936. See page 38.

\section{MARY SENNI}

Each 50c

Huge mauve blend, a sort of ashes of roses combination, with golden beard to relieve the sombreness. Produced by the great Frenchman, Millet, this iris was named for the foremost iris critic in Italy. We do not have any other iris near this color in our entire collection, and stock is offered by very few growers.

\section{MATTERHORN}

Each $\$ 15.00$

The finest and cleanest white iris we have ever seen. It does not displace Snowking, for they are entirely different in type, the latter big, bold and imposing, while Matterhorn is delicate despite its large size-ladylike, one might say. There is not a trace of any color save pure white, other than in the creamy beard. It is a beautifully branched iris, almost 40 inches tall. A Sass production, introduced by Schreiner last season.

\section{MATULA}

Each $\$ 25.00$

An indescribable apricot blend, one of the newest of this lovely series from the Sass Gardens. We have only two or three rhizomes to spare.

\section{MEHAMA}

Each 75c; 3 for $\$ 1.75$

A blend of pink and yellow, with an underlying cast of pale blue. A self in effect, although the standards are slightly lighter and reflect the glints of dustlike golden particles. A very large iris, quite early, on stems from 30 to 36 inches tall. With the sun on it, or through it, Mehama is one of the most enchanting things in the garden.

\section{MELDORIC}

Each 60c; 3 for $\$ 1.50$

Huge blue-black self, one of the richest and most striking irises ever introduced. First offered for sale in 1930 it has been so in demand that there has never been enough stock to fill the orders for it. Neither a rapid increaser nor a free flowerer, it rewards the owner with spikes of bloom that are well worth waiting for. If this iris were as consistent a performer as some varieties it would almost certainly have been a Dykes Medal winner.

\section{MICHELANGELO}

Each $\$ 8.00$

A dove-grey self, positively unique color. The flowers are of large size and excellent form. This iris is not a fast increaser nor a free bloomer, but stands alone because of its peculiar shade.

\section{MIDWEST GEM}

Each $\$ 10.00$

One of the very best new Sass varieties, a beautiful self of pale apricot yellow, lightly flushed pink. In habit of growth it is immense, and the flowers are perfectly balanced in form. Height well over 3 feet. 
MING YELLOW

Each $\$ 25.00$

In 1937 and again in 1938 this iris received more attention than any other in Mrs. Pattison's famous garden in Freeport, Illinois. It is a yellow without a faultclear, rich, smooth without venation, big and slightly waved. Habit of growth similar to Depute Nomblot. Mrs. Pattison herself considers it the most sensational iris she has ever grown and so states in her Quality Gardens catalog.

\section{MISS CALIFORNIA Each $\$ 10.00$}

Gigantic lilac pink, with the growing habits of Dauntless, one of the parents. While not the "pinkest" iris, the shade of this one is quite distinct and it surely has every attribute that one could wish for in a perfect flower. It was one of the high spots in the Salbach display garden last spring. Midseason, 48 inches.

\section{MISSOURI}

Each $\$ 2.00$

Clear, clean blue, of sensational size. There has never been sufficient stock to supply the demand for this iris, declared by some observers to be the last word in its color. Very few plants. Dykes Medal 1937.

\section{MME. MAURICE LASSAILLY}

\section{Each $\$ 10.00$}

The only new iris bearing any resemblance to the American variety Amigo. This new one from France has a more pronounced contrast of blue standards and blackish purple falls edged blue. It won the Dykes medal in 1935. The falls are heavy and velvety with edges a bit wavy. Three feet tall.

\section{MODISTE}

Each $\$ 7.50$

The feature iris selected for our cover this year. A beautiful self of pale mauve-blue, much different from other blues and lavenders now available. For three seasons this lovely seedling, actually startling in size, has drawn the attention of iris critics in the Chicago section. In color it is similar to the old and beautiful variety "Mlle. Schwartz", but MODISTE is a flower of broad hafts, full rounded shape, and ideal growing habits. Stems are heavy, well branched and around forty inches tall.

\section{MOHRSON}

Each $\$ 1.50 ; 3$ for $\$ 4.00$

Seedling of the famous iris Wm. Mohr. For almost a decade hybridizers have been trying to secure seedlings from this strange and enchanting flower, and at last we are able to offer two. Mohrson is much taller than its parent, of a deep violet color, very heavily veined still darker. H. M. AIS 1935.

\section{MONADNOCK}

Each $\$ 8.00$

We saw this iris put out its first bloom stalk in the Salbach garden in 1936, and immediately looked forward to its eventual introduction. A flower of tremendous size, solid bright rose-red in color, a seedling of Marquita. Quite late, over 40 inches tall.

\section{MOONGLO}

Each $\$ 1.50$

Very lovely and unusual blend of heavy substance. Standards are pale yellow, falls the same flushed Chinese violet. One admirer says "the golden glow of the moon all tangled up with the rosy clouds of sunset." Large flowers, ivory-like texture. A new Longfield novelty highly recommended. 


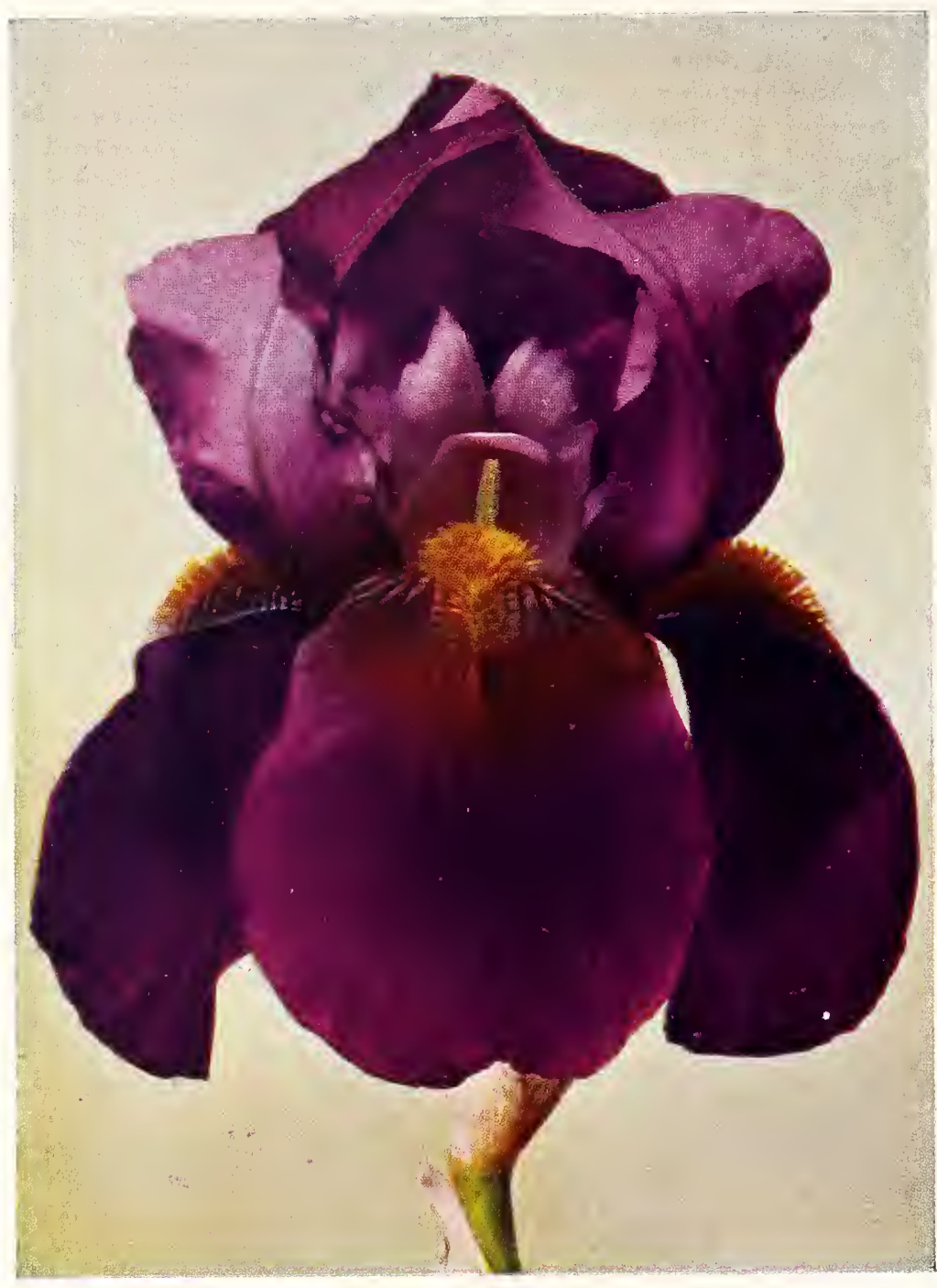

ITA ACA

\section{TEN SPOT Collection}

\section{Any 10 for $\$ 10$}

Dore

\author{
Aline \\ Amenti \\ Autumn Frost \\ Ballet Girl \\ Burning Bronze \\ California Gold \\ El Tovar \\ Golden Helmet \\ Happy Days \\ Junaluska \\ Mohrson \\ Robert \\ Vision \\ Itasca \\ Lady Paramount \\ Wotan \\ Ukiah
}

\section{ALL 18 of the above, PLUS \\ Copper Lustre, for $\$ 20.00$}

(Total catalog value, \$32)

\section{MOROCCO ROSE} heart. A seedling produced by Dr. Loomis of Colorado Springs and placed on the market by Quality Gardens of Freeport, Illinois, where it was a great favorite of the many iris judges converging there for the annual iris show. Our stock is very limited.

\section{MOUNTAIN SNOW}

Each $\$ 12.50$

Outstanding new white giant from New England, introduced by the Kelloggs in 1937. Awarded an H. M. by the iris society in 1936 as a seedling, we were much taken with it when we viewed it blooming in its home garden. The form is perfect, with very broad falls and extra heavy substance. A cool white, as the name implies, with a very faint suggestion of blue shadow on the falls.

\section{MRS. SILĀS WATERS}

Each $\$ 5.00$

Huge primrose yellow self, standards and falls practically the same shade, with some yellow markings on a cream haft. One of Dr. Ayres' newest releases. Mrs. Emigholz, the introducer, says that this iris will succeed where Lady Paramount does not, giving almost an identical garden effect. Widely branching stems, three feet and over in height.
MRS. WILLARD JACQUES

Each $\$ 5.00$

A more deeply colored flower than Noweta, which it resembles in type. It has, however, an overtone of buffy apricot, setting it apart from other pinks. This new introduction from Jacob Sass was highly regarded by critics who saw it last spring, not only because of its new color, but also for its ruffling, abundance of flowers, and wonderful garden value.

\section{NARAIN}

Each \$2.50; 3 for $\$ 6.00$

A brand new blue introduced by Quality Gardens in 1936. Has a silky texture, cream throat, and blue beard tipped soft yellow.

\section{NARANJA}

Each \$4.00; 3 for $\$ 10.00$

The leading introduction from Sidney Mitchell during the past few seasons, and the first iris of huge size with a definite orange tone. Taller even than Happy Days, and practically as large. The falls are ochraceous orange, with a yellow heart, and the standards are bright empire yellow, the beard orangeyellow. 
"The bright and shining light of the garden." Thus does the originator, Carl Salbach, describe it. The standards are bronzy gold, the falls bright and velvety carmine red, rich and glowing. The beard is fiery golden orange.

A perfect example of candelabrum type branching, with 48-inch stalks carrying a heavy quota of blooms and buds. Has been tested and found hardy under severe wintering.

\section{NOONTIDE}

Each $\$ 10.00$

Introduced this season by F. A. Thole, of Seattle. Mr. Thole says this gave him his greatest thrill of a long iris growing career. Before deciding on a definite name, he called it "yellow Depute", because it so nearly resembled Depute Nomblot in form and habit. The color is a deep solid yellow, entirely overlaid with a sprinkling of old gold. This is not to be compared with Ming Yellow, altogether different in tone.

\section{NOWETA}

Each $30 c: 3$ for $75 c$

A melting creamy pink, exceptionally ruffled, much more so than Midgard, and larger than this popular variety. Stock of Noweta is still very scarce, and as was the case last season, it is likely to be a sell-out before summer is far along. Everyone who sees it wants this frilly, pinky, fluff $Y^{-}$ ruffled dainty newcomer.

\section{OLD PARCHMENT}

Each $\$ 15.00$

A tan-cream, novel in color and perfect in shape. A Kleinsorge novelty listed for the first time. See page 9.

\section{ORLOFF}

Each $\$ 15.00$

New plicata of good size and most unusual color, being a sort of cinnamon brown in effect. The ground color is deep cream, heavily dotted and etched brown with considerable gold near the center. Along with Siegfried, a great advance step in the plicata group. Stock of both these varieties is extremely limited the country over. They are the first good tall yellow ground plicatas and everyone seems to want them. See page 29.

\section{ORMOHR}

Each $\$ 20.00$

Shown on page 16 in fairly accurate color, although the plates are not truly exact. This new seedling of the variety Wm. Mohr drew more attention from iris critics of national prominence last season than any new iris seen on the Pacific Coast. It enjoyed the greatest sale in dollars and cents of any iris we have ever introduced, and stock was sold out before July lst. We have a very limited supply of excellent rhi- zomes again this year, but those ordering late may be disappointed. Full details on page 16.

\section{PAULETTE}

Each 40c; 3 for $\$ 1.00$

Giant pale blue, a better Loetitia Michaud. From Millet, the originator of the famous and lovely Loetitia, and considered as his finest iris. Of enamellike lustre, on very tall stems, and with flaring falls.

\section{PHEBUS}

Each $25 c$; 3 for $50 c$

Clear lemon yellow, an exceedingly rapid increaser, and one of the most popular of the newer yellow irises. Fine rounded flowers, over three feet tall, with much branching. A good companion to Pluie d'Or, with its contrasting shade.
BURNING BRONZE

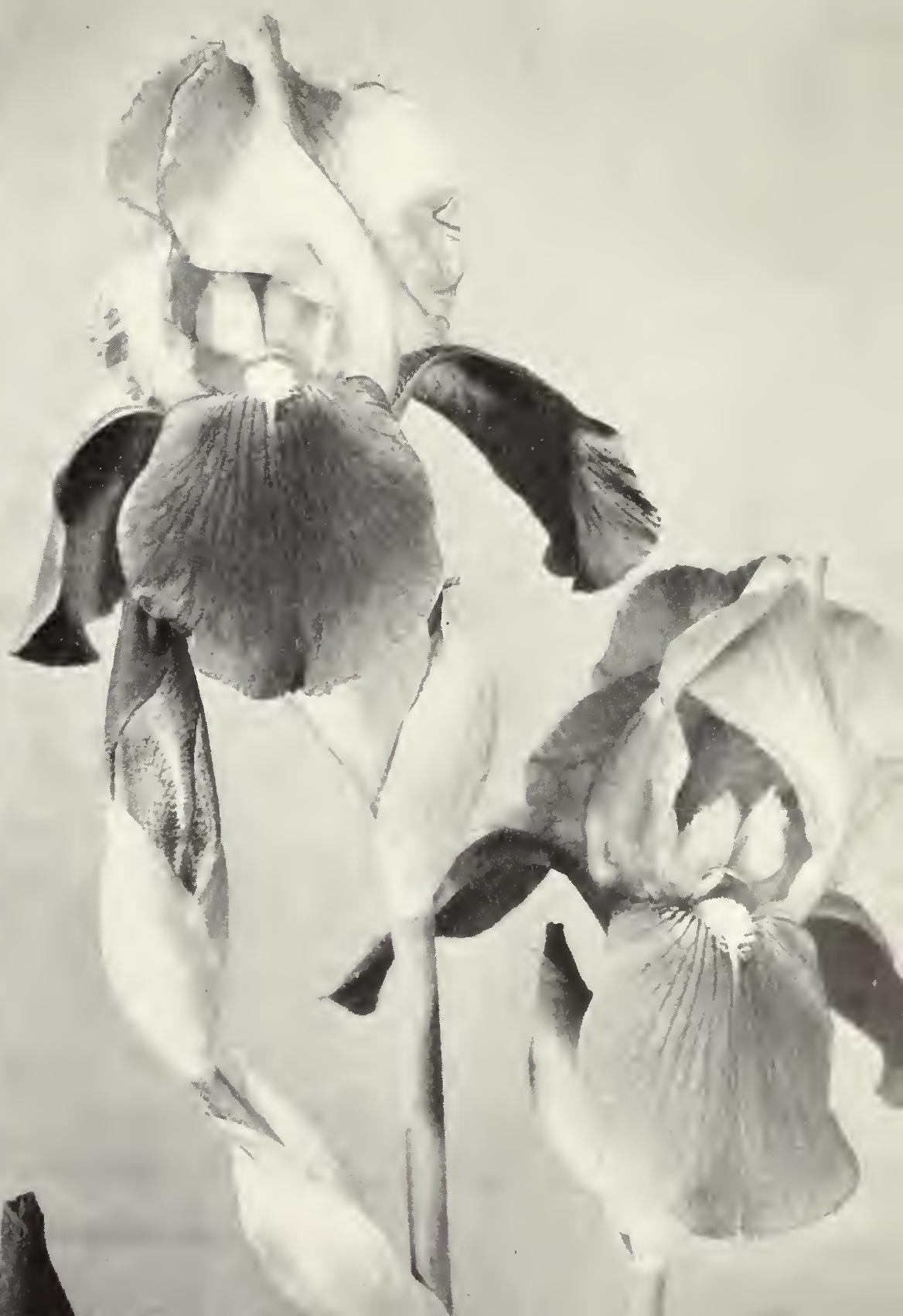




\section{PINK JEWEL}

Each 30c; 3 for $75 c$

Not a large flower, but an excellent pink toned affair where garden effect is desired. The standards are self colored, but the falls are very heavily veined deep violet pink over a lighter ground. A very rapid increaser, thirty inches tall.

\section{PINK OPAL}

Each 40c

A sister seedling of Pink Satin, of much greater size and half again as tall. The blossoms are lilacpink, self colored, and abundantly produced, although the tall stems are short branched. However, the blooms appear all along the stalks, so that the lack of branches is not apparent in the garden picture. Very beautiful, and a bargain at the price.

\section{PIUTE}

Each $\$ 10.00$

Fiery bit of color, a near approach to true red, without haft venation and lacking blue or purple in its makeup. One of Quality Gardens real quality introductions. Three feet tall, of good size, on slender stems.

\section{PRAIRIE SUNSET}

Price on request.

Possibly the most beautiful iris of all time-a glorious blend of pink, rose, apricot, peach and yellow. We were among the fortunate few who saw it two years ago and likewise among the very few who were privileged to purchase a rhizome last summer at $\$ 100$ each! We have one or two to sell this year.

\section{PRESIDENT PILKINGTON}

Each 20c; 3 for 50c

A very lovely pastel blend, which at one time bore the appropriate name of "Apparition". When Mr. Mead saw it blooming in France, he described the color as "a lavender-blue elephant tone", suffused with bronze. A huge flower, the stalks splendidly branched to 4 feet tall.

Standards are pale buff, with faint bluish and slightly rosy cast. Falls, wide and flaring lavenderblue with buffy yellow suffusion paling at the margins. Beard golden yellow.

\section{RADIANT}

Each $\$ 10.00$

Standards of burnished golden bronze, falls of glowing copper red, as bright in comparison with other iris of today as King Midas was rich among the iris available when it was first released. Of medium size and height, perfect form, inestimable garden value. Incidentally, it bloomed again in the fall in 1936, and also in 1937. Very few rhizomes for sale.

\section{RAMESES}

Each 20c; 3 for 50c

A symphony in rose, pink and buff, shading to yellow near the edges, and with a yellow glow at the heart. Heavy apricot beard. This fine hardy iris was originated in Nebraska by the Sass Brothers, and was so universally outstanding that it received the Dykes Medal in 1932. The big flowers are very freely produced, late, on 36-inch stalks. See page 22.
REBELLION

Each $\$ 5.00 ; 3$ for $\$ 12.00$

Glowing deep blood red, almost a duplicate of Burning Bronze except that the coloring is far more vivid. It is described and shown in color on the back cover.

\section{RED CROSS}

Each $\$ 2.00$

A rather bizarre contrast of bright rose-red and white, especially striking in the garden picture because of its great carrying power. It is almost an exact counterpart of Mary Geddes in markings and type, but instead of an orange or salmon cast this one appears as rose red. A Kleinsorge introduction of 1938.

\section{RED DOMINION}

Each 40c: 3 for $\$ 1.00$

Luxurious red velvet, the shade of a glass of fine wine with the light through it. The opening buds are almost black, and the full blown flowers possess a depth and richness unequalled in any other red iris. One of Dr. Ayres' masterpieces. See page . .

\section{RED GLEAM}

Each $\$ 25.00$

The most vivid red iris we have ever seen. Introduced and fully described on page 9.

\section{RED RADIANCE}

Each 50c; 3 for $\$ 1.00$

A very rich maroon red, especially telling in mass. Both standards and falls are dark, the falls velvety. Rapid increaser, very hardy, over three feet in height.

\section{ROBERT}

Each $\$ 1.25$

Somehow we have overlooked this in prior years. Last season we saw it in several Eastern gardens and it was extra fine. An iris of perfect shape and smooth substance, a chamois colored self, or perhaps a yellow-tan would better describe it. Near the haft there is a very light suggestion of pale blue. H. M. AIS 1936. Height 3 feet.

ROSARIO

Each $\$ 6.00$

Becutiful ochraceus yellow, flushed and overlaid old rose. Might be called tourmaline pink with gold suffusions extending from heart of flower into the falls. Deep yellow beard, particularly luminous in a gray atmosphere. Form broadly flaring, very large in size, finely branched stalks, 40 inches tall. Selected at blooming time last year among Mr. Thole's seedlings, his Satsuma being equally fine and a lovely companion to this one.

ROSELAND

Each $\$ 15.00$

One of David Hall's new things; a taller, larger and brighter Coralie. See page 9.

ROSY WINGS

Each \$7.00; 3 for $\$ 18.00$

Among the two or three top-most introductions during the past few years. A blend of rose and copper, with excellent form, flaring falls, large size, 40inch stems. One of the few new colors developed in iris in recent years. Very few rhizomes for sale.

RUBEO

Each 40 c; 3 for $\$ 1.00$

An outstanding red from California, of huge size, excellent branching habit, and four feet in height. Standards are deep glistening rose, falls deep maroon of heavy velvety texture. The finest red among Mohr-Mitchell introductions. 


\section{SABLE}

Each $\$ 20.00$

Extreme in color and substance, one of the few iris that might well be termed "black". Sable has every attribute that a truly fine iris should have, in addition to its novel color. Paul Cook's second introduction, the other being the magnificent E. B. Williamson. It was a significant honor which befell Mr. Cook when the iris trials in Rome, Italy, announced the winners-the grand prize and Gold Medal to his E. B. Williamson, a First Class Certificate to Sable!

\section{SANDALWOOD}

Each $\$ 5.00$

A new fawn-brown blend, showing quite a resemblance to our own introduction Far West. We have only a few rhizomes and have not seen it blooming sufficiently to give an accurate description.

\section{SANDIA}

Each $\$ 1.50$; 3 for $\$ 4.00$

Bright deep pink blend, unusual with a smoky veil. An Ohio iris critic, nationally known and whose opinion everyone respects, wrote us that it was one of the three or four finest things he saw in 1935. The blooms are large, and the stems grow to 40 inches in height.

\section{SATSUMA}

Each $\$ 7.50$

Very large flower of pale brown-pink, faintly shadowed cobalt violet, giving a warm tan effect in sunlight. Yellow beard, slightly fragrant, vigorous grower, 40 inches tall. This iris, seen as a seedling, appeared to the writer as a pure chamois colored self.

\section{SEADEEP}

Each $\$ 4.00$

Introduced by F. A. Thole, of Seattle, Wash. We saw this as a seedling in 1936, at which time we thought it the very finest blue bicolor in the world. It is a seedling of Santa Barbara crossed with Buto, and it combines the clean blue of the former in the standards with the rich blue-black of the latter in the falls, but unlike either it is just a little frilly in its segments. Tall stems, excellently branched, an abundance of huge flowers, everything to make it the complete perfect iris.

\section{SERENITE}

Each $50 \mathrm{c}$

If you care for such blends as Persia you surely will like Serenite. It is a blend of blue and gold, the standards silvery blue shading to yellowish tones at the edges, the falls bright blue with golden shadings and a brilliant orange haft. Heavy substance, widely flaring falls, stalks over three feet tall. A French origination from Cayeux.

\section{SHAH JEHAN}

Each 75c

Said to contain more colors than any other iris in commerce, this serenely beautiful flower in oriental smoky shades almost eludes any attempt to describe it accurately. Standards are creamy buff faintly edged lavender, the falls very rich velvety chestnut merging into purple, thence gradually fading out to a margin that repeats the color in the standards. Beard is very rich orange. A very late variety, tall, of large size.

\section{SIR KNIGHT}

Each $\$ 1.50 ; 3$ for $\$ 4.00$

A huge deep violet self with domed standards and flaring falls. Hafts are exceptionally broad, brightened with a rich orange beard. Over three feet in height.

\section{SHINING WATERS}

Each $75 c$

Clear and clean blue, like the reflection of an azure sky in crystal waters. There are many iris critics who declare this to be the finest of all blue toned irises. The wax-like texture of the petals has a startling contrast in the orange beards. It grows to four feet tall, with many very large blossoms per stalk. A. M. AIS 1935.

\section{SHIRVAN}

Each $50 \mathrm{c}$

With the same glowing soft brown and yellow tones found in the rare rug of this same name, this iris possesses an exquisite velvetiness and brilliance equaled by few flowers. Some of our finest pansies rival it, but seldom do we find an iris so alive and yet with such depth of tone. A seedling from the hand of Dr. Loomis, the originator of the famous Blue Velvet. Of medium height. Stock limited.

\section{SIEGFRIED}

Each $\$ 15.00$

An iris they are all talking about and one which almost everyone would buy if stock were plentiful and the price reasonably low. A flower of really huge size, pale sulphur yellow entirely overlaid with a stippling and dotting of purple. Both standards and falls are slightly waved at the edges. A buffy overtone blends the colors together. We have very fine stock, but only a limited supply. See page 7 .

\section{SIERRA BLUE}

Each \$1.00; 3 for $\$ 2.50$

A soft, clear, enamel-like blue. This iris was recently awarded the Dykes Medal of the American Iris Society for 1935. It is of tall and stately habit and carries many buds to the stalk. Together with Shining Waters, Mr. Essig has given us two of the most outstanding blue irises ever introduced. Sierra Blue is the deeper of the two. See page 26.

\section{SIR LAUNCELOT}

Each $\$ 1.50$

Gleaming chestnut red, with very bright golden brown standards. In the famous garden of $\mathrm{M}$. $\mathrm{E}$. Douglas, at Woodbury, New Jersey, it was a center of interest when the Iris Society members were guests there last spring. A flower of large size, on medium height stems, it is probably the most brilliant iris yet turned out by the Sass Brothers.

\section{SIR MICHAEL}

Each $35 \mathrm{c}$ : 3 for $75 \mathrm{c}$

Unquestionably the finest blue and purple bicolor in the world. Standards are clear blue, falls deep rich mahogany, with a beard of red-gold. Regarded as the finest iris ever to come from England and $a$ sensation wherever shown. In our own wet Northwest, in dry and sunny California, and in Nebraska, Ohio, and the colder Minnesota and New England, we found it blooming equally well. A super iris, if ever there was one.

\section{SMOLDER}

Each $\$ 7.50$

A deep blackish purple with red underglow, self colored. Beard brown, giving the flower a very deep and especially rich appearance. This is a most outstanding new seedling from Col. Nicholls, introduced last season. Fragrant, well branched, of good size, almost four feet tall. 



\section{SNOWKING}

Each $\$ 5.00$; 3 for $\$ 12.00$

We flowered this in our own gardens last season, and saw it blooming in half a dozen mid-Western and Eastern states. It is in our opinion the very finest large flowered hardy white iris, and because of our admiration for it and our faith in its future we stocked up on it and can offer a plentiful supply of good rhizomes this year. Snowking is all that one could wish for in a truly sensational flower.

\section{SOLITUDE}

Each $\$ 1.50$

Nothing gory or flashy about this flower, but for those who can appreciate subtle beauty in a sombre iris we are certain this one will be most welcome. A self of blackish mulberry, with beard in harmony. Very tall, with a profusion of large blossoms.

\section{SOUVENIR DE F. DENIS}

Each $\$ 10.00$

Cayeux's entry for the blackest iris. We flowered it last year but the stalk was not normal, being hurt by a late frost. The flower was indeed dark, almost a black self, with very flaring falls.

\section{SPOKAN}

Each $\$ 1.50$

A solidly colored deep chestnut-red, of great size -one of the very largest-with an odd coppery suffusion throughout. Once you see this iris you will make a solemn resolve to eventually own it. In the McDade garden, amongst a maze of novelties from far and wide, Spokan commanded the attention of every visitor. See page...

\section{SPRING IDYL}

Each $\$ 10.00$

Delicate pink and white, an apple blossom effect in the garden. A new Lapham seedling, see page 10.

\section{STAINED GLASS}

Each $\$ 15.00$

Fiery copper-red with the sun through it, dull copper self otherwise. See page 10 for details.

\section{ST. LOUIS}

Each 60c; 3 for $\$ 1.50$

Glossy velvety purple, with harmonious beard and mellow, pleasing haft. Of fine oval form, it is a self in color, with an abundance of flowers and excellent stems. Introduced by Robert Schreiner in 1934, it is numbered in his selection of "100 Super Iris".

\section{SUNMIST}

Each $\$ 1.00$

An immensely popular new thing from Col. Nicholls, a sort of cream and yellow blended bicolor. Standards are glittering pure white, falls creamy white with deeper central portion and golden beard. Tall, with slender stems and good branching habit.

\section{TAPESTRY}

Each 25c; 3 for $50 c$

A subtle blend of monster size, smoky mulberry in general color effect, with the center of the fall intensely colored, passing out to the smoky tones of the standards. This variety calls to mind Dr. Ayres' famous "Persia", but the dominant note is dull red instead of dull blue. TAPESTRY is a favorite of Mrs. Ayres, who admired it especially as a cut flower in the house. Shown in color on page 23.

\section{TARANTELLA}

Each $\$ 2.50$

A new pink stitched plicata, taller and larger than older varieties of that type. Ground color is snow white, neatly marked with pinkish lines about the edges of both standards and falls. Slightly ruffled.

\section{TENAYA}

Each 85c

Glowing blackish red-purple, with brownish undertone. Gives a color effect somewhat like Wotan, but the flower is of entirely different shape. Without haft venation, its richness is emphasized by a browngold beard. In the Radio City exhibit in New York in 1937 it won highest honors over scores of newer sorts. Medium height.

\section{THE BLĀCK DOUGLĀS}

Each $\$ 1.25 ; 3$ for $\$ 3.00$

Large blackish purple of uniform shade. Different in its "black" effect as compared to Black Wings in that it is on the red-purple side instead of being bluepurple, as in the case of the latter. Medium height, fine form and very velvety surface.

\section{THEODOLINDA}

Each $40 c$

A gigantic plicata comparable to the famous pair from California-San Francisco and Los Angeles. However, this new seedling is a product from the gardens of Dr. Ayres of Cincinnati, and is therefore perfectly hardy anywhere.

\section{THE RED DOUGLĀS}

Each $\$ 20.00$

Possibly more glamour was attached to the introduction of this variety than any iris in recent years. Seen in only about a half-dozen gardens last year, it drew the attention of all present. Simply colossal in size, as smooth and heavy as a piece of richest plush. It is a deep rosy-wine-red, solid at the haft with a brownish cast near the center, beard rich orange. We are fortunate to have a very fine lot of rhizomes.

\section{TIFFANY}

Each $\$ 10.00$

The third member of the great Sass plicata trio. the others being Orloff and Siegfried. It is soft yellow in color, with stitchings of bronzy-pinkish-violet, if you can visualize such a combination! Less formal in appearance than Siegfried, and gives a yellow rather than a creamy tan garden effect. Stems three feet in height. Of the three, Siegfried is the largest, Orloff the smallest-but possibly the prettiest-and Tiffany the best in all respects including size, shape, and general qualities. But many competent critics will disagree with us.

\section{TIGER-TIGER}

Each 30c; 3 for $75 c$

A red iris with tan standards, the falls appearing more nearly true red than any other iris we have seen. A heavy blooming Wareham seedling with very large well formed blossoms. It bears our sincere recommendation. 
One of the new Hall seedlings, a Mary Geddes garden effect, but smoother and otherwise finer. See page 10.

\section{TREASURE ISLAND}

Each $\$ 7.50 ; 3$ for $\$ 18.00$

A truly gigantic flower of bright, clear, rich yellow. Tall stems, not a trace of Dykes blood in its parentage, hardiness beyond question. Treasure Island is the nearest to ideal of any of the new yellows we have seen, because there is neither the telltale purple flecking which eventually crops out in those of the Dykes strain, nor the oftimes tender constitution accompanying them. Still other fine new golden hued introductions possess a suffusion of olive on the haft, but not so with this one. The illustration on page 34 is an exact reproduction in every detail except size, which is reduced to fit the page.

\section{TUSCALOOSA}

Each $\$ 10.00$

A larger and taller Shirvan, almost identical in color. We saw this at least three feet tall in Nashville, splendidly branched and with large blossoms. A Col. Nicholls seedling, introduced by his son, Jesse.

\section{UKIAH}

Each $\$ 1.25 ; 3$ for $\$ 3.00$

A tall deep velvety brown iris, along the lines of Mrs. Valerie West. Of great size and perfect form, with sturdy stalks and broad foliage.

\section{VALIANT}

Each $\$ 2.00$; 3 for $\$ 5.00$

A blend of old gold and violet blue, the standards especially fine. The haft is brilliant gold, balance of the falls wistaria violet. Bright orange beard. From a cross made in Mr. Mitchell's California garden by Miss Sturtevant.

\section{VENUS DE MILO}

Each 30 c; 3 for $75 c$

This pure white, of a warm creamy tone, is now generally accepted throughout the nation as the very finest, all-round, most dependable under all conditions, of any white iris that grows. Last season our large stock of many hundreds of rhizomes was sold out, and because of so much favorable comment we anticipate a heavy call for it again this summer. One of the greatest successes from Dr. Ayres, of Cincinnati. A. M. AIS 1935. Runner-up for the Dykes Medal, 1936.

\section{VERT-GALANT}

Each $30 c ; 3$ for $75 c$

Brilliant coppery red, with copper-fawn standards. A giant sort that has the habit of putting up from two to four huge stalks from each rhizome. The falls are edged with the lighter fawn color of the standards, and the haft is beautifully marked with cream and brown. This variety is not only a striking exhibition flower, but it has extra good carrying quality, and the four-foot spikes dominate the garden. Another Dykes Medal winner.

\section{VICTORY}

Each $\$ 10.00$

Huge violet purple, in style and color quite unlike other purple iris. See page 11.
There are many variegata blends, such as El Tovar and Crown Prince, which contain much brown and deep orange, and which are magnificent iris. But Vision carries no blending of tones whatsoever, a contrast of brightest clean yellow standards and very velvety red-brown falls, margined yellow.

\section{WABASH}

Each $\$ 5.00$

A new iris so far in advance of others of similar color combination that they are simply not in the race. With clean white standards and bright purple falls, it might have been called "Elk's Temple", so well does it call to mind the colors of that well known fraternal organization. The flowers are large and are borne on well branched stalks reaching almost forty inches in height.

\section{WASATCH}

Each \$2.50; 3 for $\$ 6.00$

The largest plicata and one of the largest of all iris. Of the San Francisco type, with very broad falls and heavy substance. Color is clear white, with blue stitching on the haft.

\section{WAVERLY}

Each $\$ 10.00$

A 40-inch clear light blue, highly commended by all judges who have seen it. Originated by Tom Williams, of Nashville, Tenn. Some friends have advised us that this is the bluest one yet, but we have not flowered it as the catalog is written.

\section{WINNESHIEK}

Each $30 c ; 3$ for $75 c$

A gigantic blue-black, ruffled, and with a pearly edge on the falls. Here is an iris which suddenly sprang into prominence when it was exhibited in Lincoln, Nebraska, at the American Iris Society meeting four years ago. Every critic fell for its unusual style, broad segments and rich color-and so will you! See page 23.

\section{WM. MOHR}

Each 25c; 5 for $\$ 1.00$

This strange and beautiful hybrid is named for one of the world's most famous hybridizers, and is considered as his greatest piece of work. The entire bloom is a self color of pale lilac, closely netted and veined with deep violet, producing a weird, yet very lovely effect. In some ways it resembles the variety "Susiana", but lacks the dullness of this older sort, and is not at all difficult to grow. A monster flower, produced on stems up to 30 inches tall.

\section{WOTAN}

Each $\$ 1.00$

Here is the darkest, richest, and largest, of all the very deep blends. The velvety purple-brown texture extends clear into the throat, and were it not for the somewhat short stem, we would be inclined to rank this ahead of any dark iris that grows. However, the foliage is very bold and the stalks are heavy and in keeping with the size of the blooms. Height is the sole limitation-about 28 inches. 


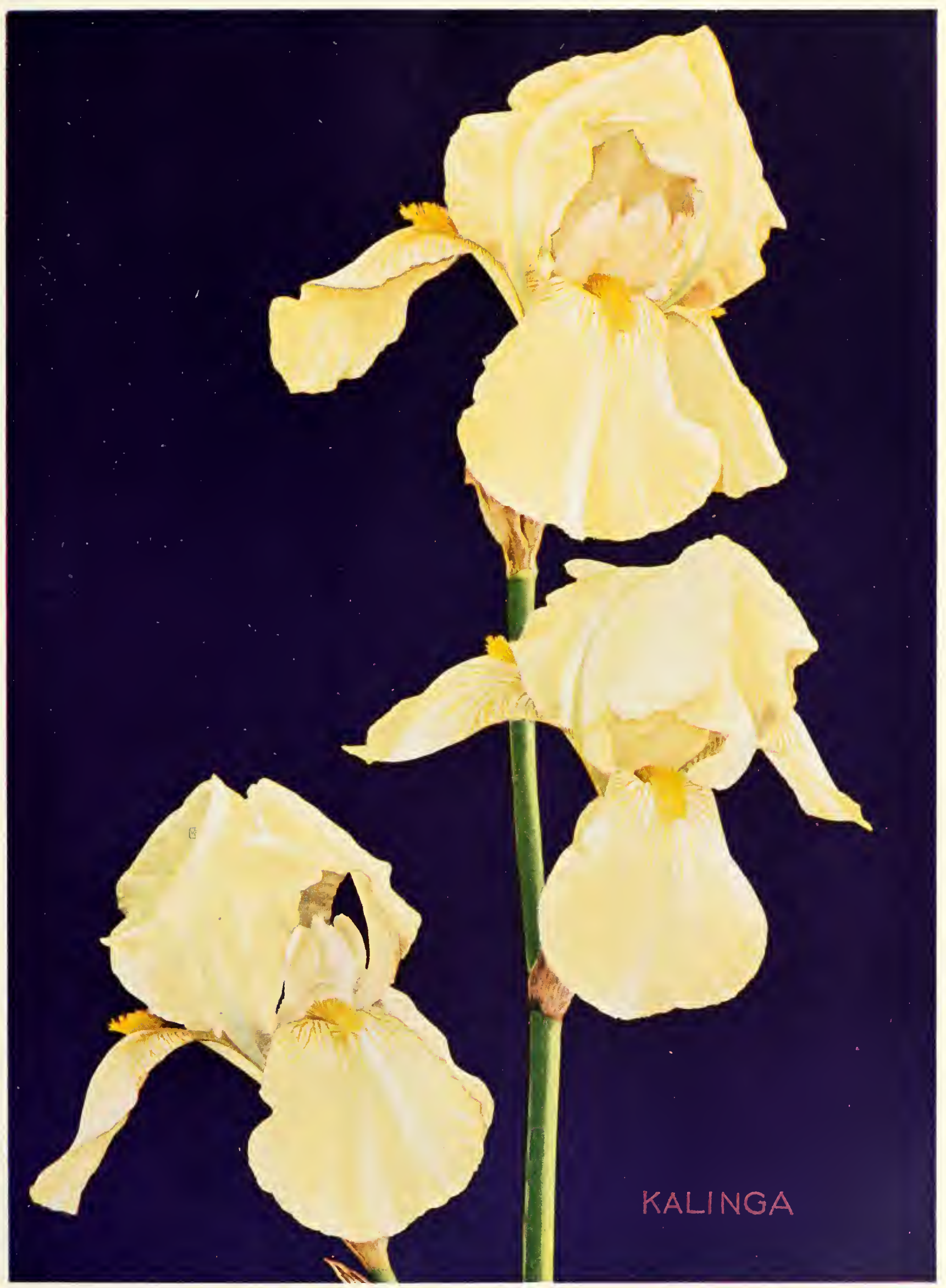




\section{THRIFT Collection}

\section{Any 12 for $\$ \mathbf{3 . 0 0}$}

Alta California

Autumn Dawn

Blackamoor

Golden Flare

Imperial Blush

Mary Geddes

October Opera

Red Dominion

Theodolinda

Ethelwyn Dubuar

Paulette

Frost Queen

Pink Jewel

Jerry

Mary Senni

Pink Opal

Shirvan

Tiger-Tiger

Or you may substitute any from the collection on page 23 . 
- Are you one of those flower lovers who cares but little for names, who has only a dollar or so to spend, and who wants the greatest number of varieties with the widest diversity of color for the least possible expenditure?

If you are, or if you are a curious soul with a yen to take a peek at our product before chancing a larger order, here is the answer:

For $\$ 1$... we will send you not less than TEN iris, all different, postpaid, but without labels. Some of them are varieties of which we had too little stock to list in the catalog, others will be among those listed in this catalog but on which we are overstocked. None will be old or outdated trash commonly offered in "un-named" collections.

For \$2 ... the same proposition but 25 sorts, all different!

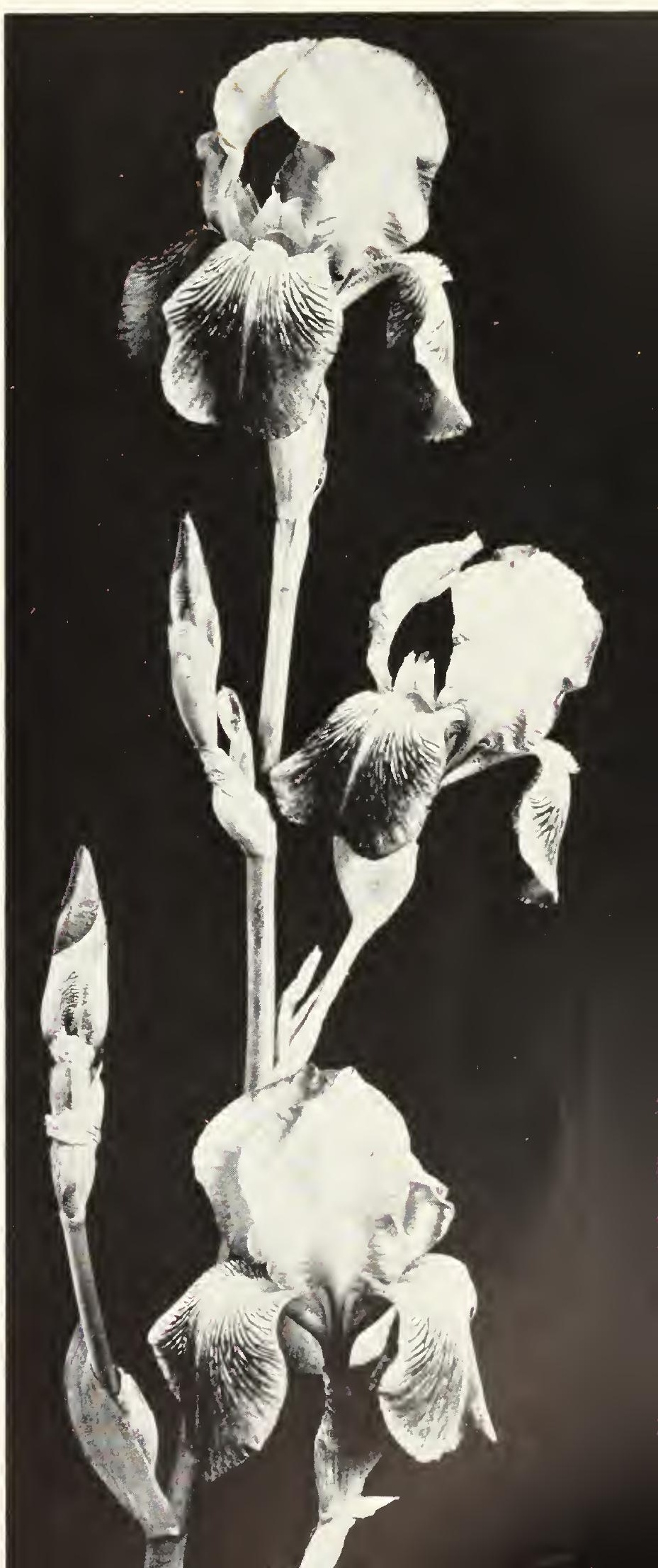




\section{Intermediates and Fall Bloomers}

Fall blooming irises have been rapidly coming into prominence, especially with the advent of new colors and better varieties.

Time was when any old iris, no matter how lacking in form, clarity of color, or other desirable features, was in popular demand if it exhibited fall blooming tendencies.

These should make a fine addition to anyone's Autumn garden. They are the latest vogue in irisdom.

Cosette, Ivory Elf and Red Orchid are NOT fall bloomers.

\section{AUTUMN DAWN}

Each $50 \mathrm{c} ; 3$ for $\$ 1.00$

Fall bloomer of blended old gold and pink-certainly an advance in this type. In California, where it originated, it blooms almost continuously from August through the winter, commencing again in April. Height, two feet. Very rapid increaser, in no way tender.

\section{AUTUMN FROST Each \$2.00; 3 for \$5}

A large flowered pure white, with golden haft and beard. A fall bloomer.

\section{COSETTE}

Each 50c: 3 for $\$ 1.00$

Newly introduced by the Sass Brothers in 1936, Cosette is offered as a fine, large, broad petaled white intermediate with every good point.

\section{ELEĀNOR ROOSEVELT}

Each 20c; 3 for 50c

Deep fluorite purple self, with very rich falls. The opening flower is almost black, and the heavy blue beard tends to increase the depth of color. This is the leading fall-blooming iris in commerce today, because it increases very fast, is most reliable in flowering habit, and is one of the most beautiful irises in the garden regardless of its added value as a re-bloomer.

\section{EVELYN PULLAR}

Each $\$ 10.00$

A real winter bloomer, one that begins to flower after the usual fall bloomers have finished. A continuous crop of buds carries the parade of flowers well into spring. Protected from snow and freezing weather by a box-like frame, one never would guess that the accompanying picture was made during Christmas week! Color is a medium to light blue, with bright orange beard. Stock very limited.

\section{FRANKLIN ROOSEVELT}

Each $\$ 1.00 ; 3$ for $\$ 2.50$

A sure-fire fall blocmer, but not very rapid of increase. Tall, well branched, bright red purple in color, with blue blaze on the falls.

\section{FROST QUEEN}

Each 50 c; 3 for $\$ 1.00$

Frostv white, exceptionally free bloomer, and of perfect form. This has proven very dependable as a re-bloomer in Kansas, Nebraska, and Tennessee, as well as on the Pacific Coast. A succession of new bloom stalks follow each other throughout the fall.

\section{GOLDEN HARVEST}

Each 50c

Standards olive yellow, tinted blue at the base; falls citron yellow, tinted blue near the haft. This introduces a bright and cheerful note in the fall garden, and is the one yellow autumn flowering iris that is obtainable at a low price.

\section{IVORY ELF}

Each $\$ 2.00 ; 3$ for $\$ 5.00$

The falls are smooth and flaring, creamy with ivory center; standards are creamy white with golden flec's, very foamy in effect. No other intermediate resembles it, and we are certain that it will be a very happy companion to tulips and other flowers of early spring. Height 20 inches.

MARTIE EVEREST

Each $\$ 2.00$

A tall and very well branched fall bloomer, the best blue autumn flow. ering variety.

\section{OCTOBER BLAZZE}

Each $\$ 1.00 ; 3$ for $\$ 2.50$

A fine big glowing red, along the lines of Indian Chief, but it is a persistent autumn bloomer. Much brighter in color than October Opera and larger in size.

\section{OCTOBER OPERA Each 50c; 3 for \$ 1}

A new color in cutumn flowering sorts, a rich wine-red. It is brighter than the old Opera, much larger, and is also taller. This is a fine grower, and in the fall in our garden it was covered with flowers. Of course it also blooms in the spring, with the intermediates.

EVLYN PULLAR

Each 25c; 3 for 50c RED ORCHID

Very early flowering intermediate, glowing like a coal of fire in the morning and evening light. Deep red in effect, violet-carmine technically, it is so recent as to be hardly known as yet but is certain to be popular when the public has seen it in flower. Height 28 inches.

\section{SOUTHLAND}

Each 75c; 3 for $\$ 1.50$

The Sass Brothers have given us most of our autumn flowering irises, and now we are indebted to them for this fine big yellow. The color is deep lemon chrome, with flowers of large size and thick heavy substance. Flaring falls and domed standards, the stems low branched. Vigorous in growth, two feet tall.

\section{Fall Blooming Collection}

Eleanor Roosevelt, Golden Harvest, Ultra, Autumn Dawn, October Blaze, and Southland, for \$2.00. 


\section{Iris Miniatures \\ for the Rock Garden, the Border or Flagstone Path}

They lead the parade! Right with the Daffodils come the Dwarf Iris. Short in stature and delicate in structure, they are none the less stout of heart and brave the icy blasts and cold rains of early spring with the courage of a Spartan.

Most Dwarf Irises multiply very fast, creating a sheet of bloom, and later on, a dense mat of green foliage. Long recognized as admirable subjects for the rock garden, and as an edging plant in the flower border, these miniatures are perfectly adapted to embellishment of the flagstone path. Scatter them here and there along the intervening spaces. The springtime showing will delight you.

\section{CYANEA}

Each $25 \mathrm{c} ; 3$ for $50 \mathrm{c} ; 10$ for $\$ 1.00$

Glowing violet, with white beard. Large flowers and fine foliage. Fragrant.

\section{DIXMUDE}

Each $25 \mathrm{c} ; 3$ for $50 \mathrm{c}$

Standards analine blue, falls brilliant wine. A striking contrast.

\section{DR. MANN}

Each $25 \mathrm{c} ; 3$ for $50 \mathrm{c}$

A dusky blue and purple bicolor. Good height for a dwarf, and late-midseason flowering.

\section{ELF QUEEN}

Each \$1.00; 3 for $\$ 2.00$

From the garden of Hans Sass we obtained this new snow white miniature, and it is being introduced at this time. Much more dwarf than the variety Snow Maiden, the pure white flowers having a slight cool green tinge.

\section{FLORIDA}

Each $25 c$; 3 for $50 c$

Bright primrose yellow. A gay and fragrant little fellow with lots of flowers.

\section{KEEPSAKE}

Each $50 \mathrm{c}$

New type of dwarf iris introduced in 1936 by the Longfield Iris Farm, originated by Paul Cook. This one is of brightest yellow, with slender, graceful stems bearing from one to three flowers, 12 inches tall. Fountain-like foliage, with an amazing number of flower stems per plant. Limited stock.

\section{NEOLA}

Each $40 \mathrm{c}$; 3 for $\$ 1.00$

Very odd blend of brown and mauve, lovely and most unusual. Although low in price the stock of this is scarce. A fall bloomer.

\section{ROSE MIST}

Each $25 \mathrm{c} ; 3$ for $50 \mathrm{c}$

Soft rose-lilac, ten inches high. One of the newer things.

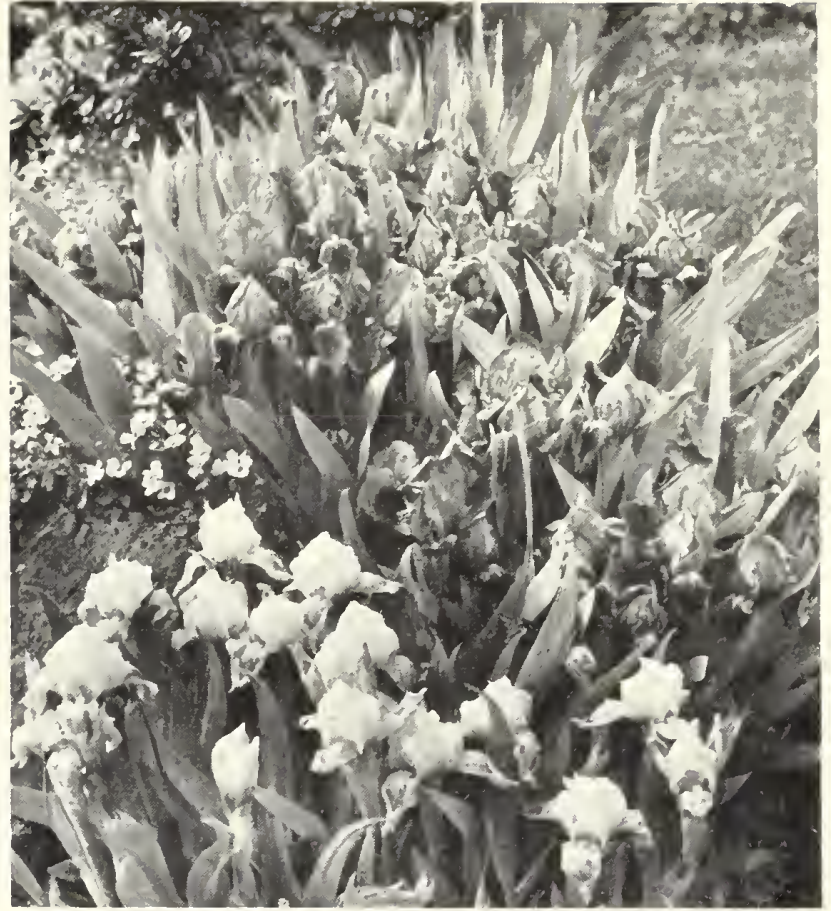

SAMBO

Each 30 c: 3 for $75 c$

Well named-a blackish garnet, with rich buds. Seldom offered.

\section{SNOW MAIDEN}

Each 50c

A new white of very low growth, 10 inches, clean and lovely, with a faculty for producing an almost unbelievable quantity of bloom. Like a dr.ft of newly fallen snow.

\section{T A MPA}

Each $50 \mathrm{c}$

Along with Keepsake, Tampa was introduced by the Longfield Farm as a new type dwarf. Very red for a dwarf, on slender l4-inch stems, the flowers about 2 inches each way. They are lavishly produced above foliage that is in itself graceful and $a$ fit subject for the rock garden. Limited stock.

TITANIA

Each 50 c; 3 for $\$ 1.25$

Deep buttercup yellow, large, well formed. This is another late variety and one of Sass's new things. TONY

Each $25 \mathrm{c} ; 3$ for $50 \mathrm{c}$

Very brilliant ruby red, almost black unless in sunshine. In early morning or at sundown it glows like fire. One of the very best regardless of price.

ULTRA

Each $25 \mathrm{c} ; 3$ for $50 \mathrm{c}$

One of the largest flowered dwarfs, as well as one of the tallest ( $\mathrm{l}$ foot), and in addition is one of the bluest irises grown. Besides all this, it is a most reliable autumn re-bloomer!

\section{DWARF IRIS COLLECTION}

ONE EACH, Tony, Florida, Rose Mist, Neola. Dixmude, and the new white Elf Queen, for $\$ 1.50$. THREE of each, for $\$ 3.50$.

Please remember that these are miniature types, and the rhizomes are indeed tiny compared to other iris! 


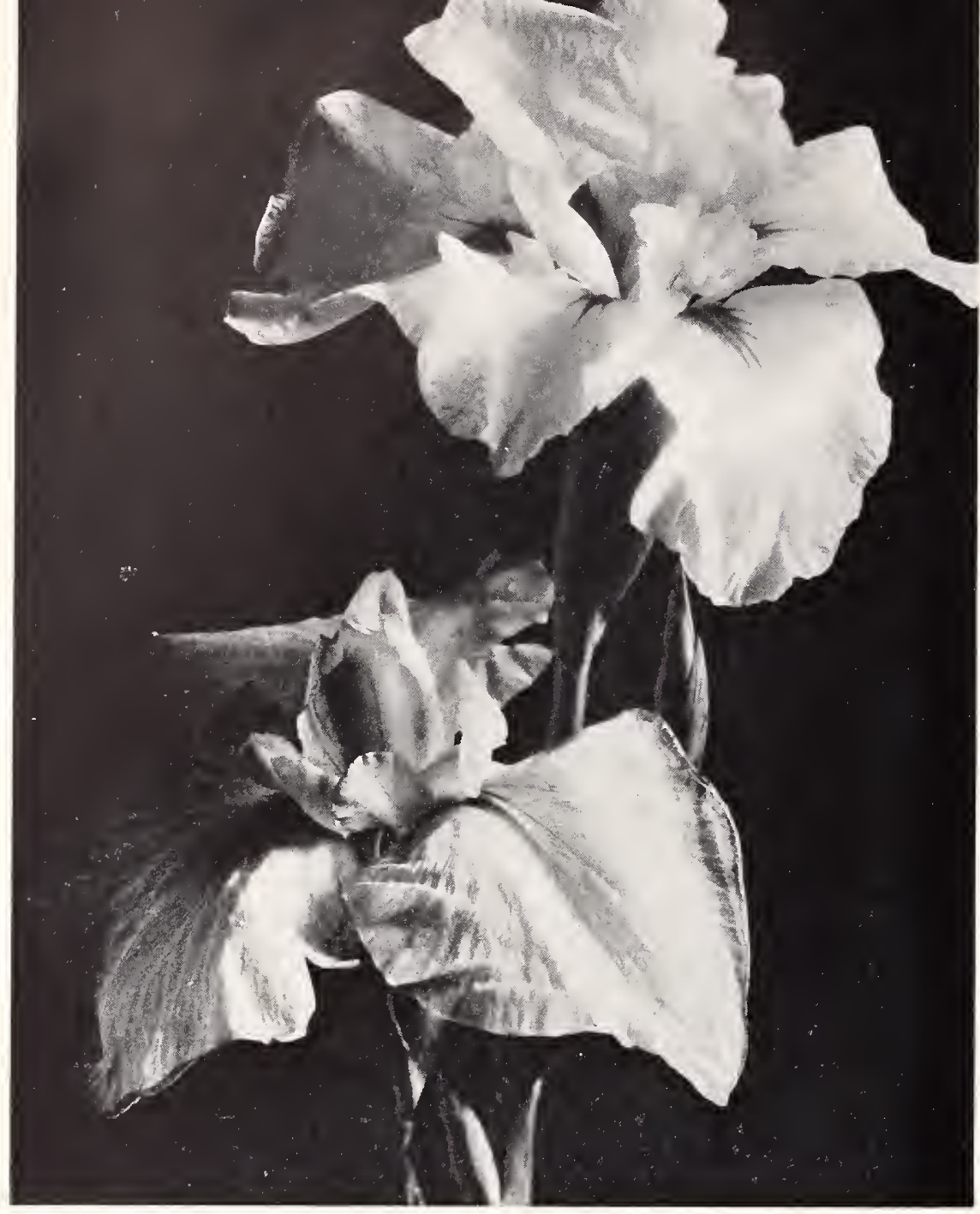

\section{JAPANESE IRIS}

Withdrawn from our catalog two years ago because of scarcity of stock, we now take pride in again offering a wide selection of these gorgeous late June and July flowering plants. Included in the complete list on page 44 are four novelties which we brought in from Japan and which are now released for sale for the first time.

\section{Japanese Iris Collections}

Large, vigorous plants, with two or more fans each, correctly labeled and postpaid, and packed in damp moss to insure freshness when they reach you.

The 5 Varieties Starred for $\$ 1.75$

Your choice of any 10 for $\$ 3.00$ (except last 4)

The ENTIRE LIST of 20 for $\$ \mathbf{5} .00$
*1. Eleanor Parry
11. Marvella
2. Osamaku Miyo
12. Collingwood
3. Cloudy Sky
13. Shiga
*4. J. A. Hayden
14. Suri
5. Talmanya
15. Vernon
16. Kohio
*6. Monija
*7. Martha Kemp
17. Perfect Peace
18. Otomene
8. Jeanette Parry
19. Purple Glory
9. Cloud Dress
20. Aifukurin

Late in the summer, betier make one or two second choices from the regular list, in case we are sold short on some of the above.

\section{CULTURE OF JAPANESE IRISES}

"It is NOT TRUE that Japanese Irises must have bogland or even water in which to bathe their roots. They love moisture, but will flourish in any good garden soil if water is applied in abundance and if the exposure is sunny. The latter point is important. It is useless trying to grow Japanese Irises in a shady spot. Sunlight and moisture are the two requisites for success with these plants.

"Let it be remembered that this type of Iris takes an entirely different tret it be the surface of the ground, the crowns should be buried two inches.

"Peat can be added to advantage to soil where Japanese Irises are to go. Unlike the Bearded Irises, which delight in lime, the Japanese forms prefer a soil which is somewhat acid. Lime should never be used with them. It is also important that the ground be kept well cultivated, never being allowed to become hard or dry. A summer mulch of pulverized peat lessens the amount of hoeing necessary and helps to hold the moisture.

"The location should be one where the drainage is good, even though it be close by a pond. These Irises like to have their roots reach water in summer, but stagnant water must not stand around the clumps, and it is imperative that they should not be caked over with ice in winter.

"Japanese Irises must have plenty of room, and must never have competition from weeds or grass. If they are used in a general garden away from water, a spot should be prepared for them by digging out a foot of earth and working in an abundance of well rotted cow manure. If the earth is at all heavy set the divided clump on a little mound of sand. When winter comes a light mulch will be needed.

There is only one way in which to get an abundance of large flowers, and that is to supply water with a generous hand during the spring before the buds open." -Extract from "Horticulture" Magazine. 


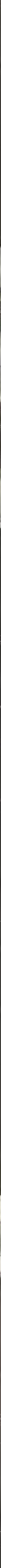




\section{AIFUKURIN}

sqle. White ground, suffused and heavily edged violet, petaloid stamens edged petunia violet. An exceptionally beautiful variety. See page 43, lower right.

\section{BEAUTY OF YAMAMOTO}

Each $\$ 5.00$

A new one from Japan, perfectly huge, very deep ultramarine blue self, deep gold center.

\section{CATHERINE PARRY}

Each $50 \mathrm{c} ; 3$ for $\$ 1.00$

Dbl. Blue, ovrlaid with rosy red glow; high tufts in center lend distinction.

\section{CLOUDY SKY}

Each $50 \mathrm{c} ; 3$ for $\$ 1.00$

Dbl. White with crimson tipped petals. Very fast grower.

CLOUD DRESS

Dbl. Grey, lined lightly with purple veins.

COLLINGWOOD

Each $75 \mathrm{c} ; 3$ for $\$ 1.75$

Sgl. One of the Kemp varieties, very pinkish in tone, slightly ruffled.

\section{CONST ANCE}

Each 75 c; 3 for $\$ 1.75$

Pale blue ground, flushed and feathered mauve, yellow at the throat.

\section{ELEANOR PARRY}

Each 50c; 3 for $\$ 1.00$

Dkl. Claret red, flamed white and blue as the flower ages.

\section{GENIIYAMA}

Each $75 \mathrm{c} 3$ for $\$ 1.75$

$\mathrm{Dbl}$. One of the largest, very tall, a metallic light purple overlaid klue; orange blotch.

\section{HATSUKI}

Each $50 \mathrm{c}: 3$ for $\$ 1.00$

Sgl. A strikingly blue flower for a Jap iris, uniform in color, neat in appearance, prolific bloomer.

\section{HARMONY}

Each $75 \mathrm{c} ; 3$ for $\$ 1.75$

Sgl. Ruffled oxide blue, veined and edged lilac pink, with orange blotch.

\section{J. A. HAYDEN}

Each $75 \mathrm{c} ; 3$ for $\$ 1.75$

Dbl. Giant porcelain white, with edges of petals shading off into light blue. A very large and heavily textured iris.

\section{IEANETTE PARRY}

Each 50c; 3 for $\$ 1.00$

Sgl. White, very large falls delicately hair-lined with soft blue. Deep amethyst violet standards.

\section{KARAHASHI}

Each $\$ 5.00$

Dbl. Deep magenta-lake in color, very vivid, with extra broad petals waved at the edges. A lovely rose red tone, with blossoms of largest size. Recently imported from Japan.

\section{KOHIO}

Each $75 \mathrm{c} ; 3$ for $\$ 1.75$

Dbl. Light lavender ground, densely mottled and veined purple.

\section{KOKO-NO-IRO}

Each 50c; 3 for $\$ 1.00$

Dbl. Dark wine red self, orange blotch in center; a very double variety that blooms extra late. A striking red effect.

\section{KUMONO}

Each 50c: 3 for $\$ 1.00$

Dbl. Lavender, with very fine feathering and veining of white, yellow center

\section{KURUMA-DOME}

Each $\$ 2.50$

Dbl. Another new one which we imported from Japan. This one is white with a narrow stitching of reddish purple, something like the plicatas in bearded iris

\section{LAWRENCE}

Each 75c; 3 for $\$ 1.75$

Sgl. A very large and broad petaled light reddish violet, heavily sanded white. A Kemp introduction.

\section{MARJORIE PARRY}

Each $50 \mathrm{c} ; 3$ for $\$ 1.00$

Dbl. Huge light lavender, almost white, with tufted center. Some flowers come pure white, others clear lavender, still others blended together. Fine form and a vigorous grower.

\section{MARTHĀ KEMP}

Each $50 \mathrm{c} ; 3$ for $\$ 1.00$

Sql. The most prolific growing sort in our collection. A Kemp introduction of deep lilac pink, brushed venetian blue.

\section{MARVELLA}

Each $50 \mathrm{c} ; 3$ for $\$ 1.00$

Sgl. Phlox purple, splashed phlox pink; a Kemp variety.

\section{MIYUKI-GURUMA}

Each $\$ 5.00$

Dbl. A most spectacular gigantic flower of clear white with very broad frosted edge of brilliant crimson. One of the newest novelties direct from Japan. Limited stock.

\section{MONIJA}

Each 50c; 3 for $\$ 1.00$

Sgl. Rich crimson wine, with hair line edge of white. This is a robust growing iris with great masses of bloom, medium in size, quite tall, very velvety in appearance.

\section{NEPTUNE}

Each 75c

Sgl. Solid wine red with orange center. The tallest Jap in our collection. Very few plants this year.

\section{NISHIKA}

Each 75c; 3 for $\$ 1.75$

Sgl. Extra large bright rose, heavily marbled and splashed with white. One of the finest.

\section{OSAMAKU MIYO}

Each $75 \mathrm{c} ; 3$ for $\$ 1.75$

Dbl. A great ivory or creamy white flower, entirely covered with tiny web-like blue veins. Styles deep blue violet. We have propagated a large stock and offer it at a price far below its real value.

\section{OTOMENE}

Each $\$ 1.00$

Sgl. The largest Japanese iris grown, some flowers actually attaining a diameter of 1 foot! A very tall royal purple, overlaid with a smokey cast. See picture on page 43, upper left.

\section{PERFECT PEĀCE}

Each $\$ 1.00$

Dbl. A new white originated here in Oregon. Of extremely double form, with a crest-like center surrounded by golden veins.

\section{PRESIDENT HARDING}

Each $\$ 1.50$

$\mathrm{Dbl}$. A rare variety that is much sought after, since it is of an unusual blue tone and extra late. Very heavy substance. Our stock is extremely limited.

\section{PURPLE GLORY}

Each \$1.00; 3 for $\$ 2.00$

Dbl. Originated also by Mrs. U. G. Smith, who gave us the lovely white, Perfect Peace. This iris is a giant in size, very deep red purple in color, with a silky sheen. A very rich piece of color.

\section{RICHMOND}

Each $\$ 1.00$

Sgl. Now for the first time in several seasons we are able to again offer a few plants of this Kemp variety. Of richest velvety roya: purple, lightly splashed clear white. Few plants.

\section{RISHONO}

Each 75c; 3 for $\$ 1.75$

Dbl. A very heavy flower of rich deep purple, waved and fluted at the edges, different form than most others.

\section{ROMANCE}

Sgl. Heavenly blue, marbled with pinkish lilac

\section{SHIGA}

Each 50c; 3 for $\$ 1.00$

Dbl. A bold and massive flower, reddish blue in color, heavily striped and veined white, giving an effect of oriental porcelain.

\section{SURI}

Each $75 \mathrm{c} ; 3$ for $\$ 1.75$

Sql. Described by some as a "mouse gray" self. This is such a free bloomer that it almost forgets to propagate itself!

\section{TALMANYA}

Each 50 c; 3 for $\$ 1.00$

Sgl. Pale king's blue, splashed lighter blue; a finely ruffled sort of large size.

\section{VERNON}

Each $75 \mathrm{c} ; 3$ for $\$ 1.75$

Sgl. Bright lavender blue on pink ground, orange center; a very large flower. 


\section{ORIENTAL POPPIES}

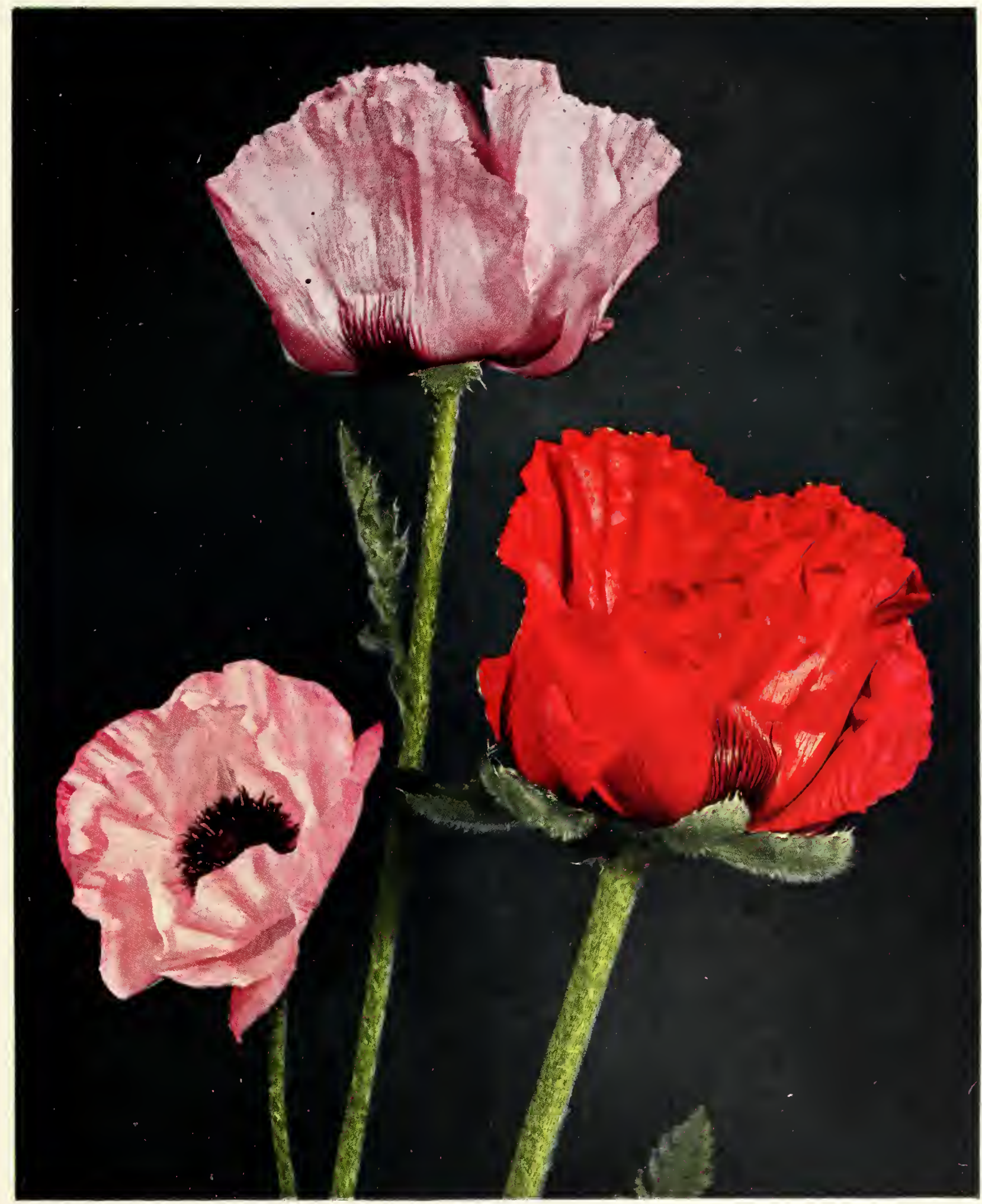




\section{Oriental Poppies \\ for Barbaric Splendor}

\section{CULTURE OF ORIENTAL POPPIES}

There is nothing more brilliantly attractive-more strikingly noticeable in any garden-than a clump of Oriental Poppies.

Many times I had bought plants, only to have them die, and many times I had planted seed-but with very little success-simply because I did not know how to care for them. Finally I bought plants in the dormant season and set them out. After becoming established in their new home they made wonderful growth in the Fall.

Oriental Poppies are quite hardy, and stay green most of the winter under a light covering, which they should have. When spring comes the plants make rapid growth and very soon big fat buds appear. In a few days, these buds burst into a radiant brilliance, to my joy and satisfaction.

Do not buy Poppies in the spring and expect them to do their best. Buy them in their dormant season, in August or early September-carefully plant them-let them get their roots firmly established-- the little feeding roots active and ready for quick work in the spring, and you will have glorious Poppies in your garden, and a thrilling satisfaction in your heart.From "The Flower Grower."

\section{AMUN RA}

Each $\$ 1.50$

Red-orange, 28 to 30 inches high, flowers $8-9$ inches across. Outstanding quality.

\section{CAVALIER}

Each $\$ 1.50 ; 3$ for $\$ 4.00$

Larger than the enormous variety Wurtembergia, perfectly formed, and lasts extra long in flower. The color is glowing cerise.

\section{ENCHANTRESS}

Each $\$ 1.00$

Soft lilac-rose, a near approach to lavender. Opens perfectly, holds its color remarkably well for this shade. A true novelty of exceptional merit. Only a very few plants.

\section{JEANIE MAWSON}

Each 75c

Melting peach-pink, very lovely and quite different from all others in its most attractive coloring. Large and fine.

\section{RING GEORGE}

Each 50c

Large fringed flowers of brilliant scarlet, petals deeply cut like a parrot tulip. Medium height, fast increaser.

\section{LORD LAMBOURNE}

Each 50c

Fringed, like the foregoing but with heavy black blotches and a slightly different shade.
MANDARIN

Each \$1.00; 3 for $\$ 2.00$

Appropriately colored Chinese red, of great size. There are no basal spots on the huge flowers. Seldom listed, it was declared by many of our visitors last year to be the finest and most spectacular poppy of all.

\section{MASTERPIECE}

Each $\$ 1.00$

Lilac color, marvelous flower, but should be grown with slight protection from the sun to prevent fading of the delicate color.

\section{MRS. FISCHER}

Each \$1.00; 3 for $\$ 2.50$

Extra large, very deep red poppy on the tallest stems of any in our collection. It will easily reach 4 feet regularly, with uniformly perfect flowers, silky in texture, one of the very best at any price.

OLYMPIA — Sold out for 1939.

\section{PEARL PINK}

Each $\$ 2.00$

Very fine and distinct; a delicate shade of light pearly pink, vigorous and prolific. Appears like one large tulip within a larger one. Its delicate color cannot stand the strong reds and bright salmons, and to see it at its best, should be planted with blue iris or an early delphinium. Stock limited. Medium height. 


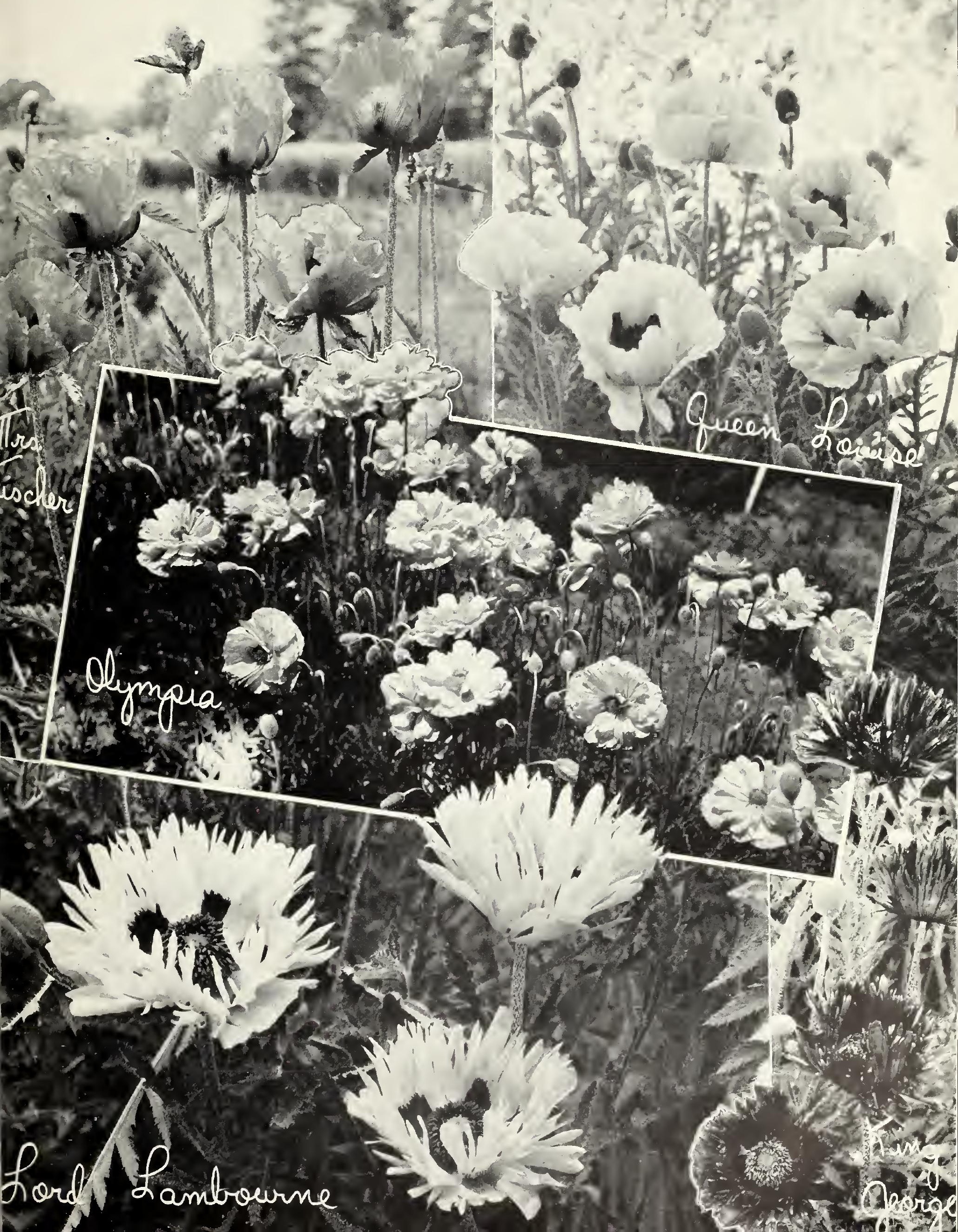


Large deep flowers, entrancing shade of pink with immense black spots at base.

\section{PERRY'S BLUSH}

Each $\$ 1.00$

Blush white, beautifully formed and a profuse flowering variety. Stock of this is quite scarce.

\section{PROSERPINE}

Each $\$ 1.00$

Most brilliant Chinese red, the center alive with black stamens. Of great size, flowering over a very long period. Shown on page 45.

\section{QUEEN LOUISE}

Each 75c

A melting strawberry pink flower of good finish, with prominent black and red base spots. To 40 inches tall.

\section{RED LACQUER}

Each $\$ 1.50$

A new deep dark red, of strong appeal. Stiff erect stems to 44 inches tall. Blooms 7 to 9 inches across. Well named.
Brilliant, huge, entirely novel in color, this blend of peach and apricot, entirely overlaid salmon, is unlike any poppy we have ever seen. Very late, and a vigorous grower.

\section{TRILBY}

Each $\$ 1.00 ; 3$ for $\$ 2.50$

One of the last to bloom. Dark, lustrous, deep red, the petals having a plaited appearance. Very large, and one of the finest of all poppies.

\section{WATTEAU}

Each \$1.00; 3 for $\$ 2.50$

Pure flesh-coral; covered with flowers. No blotch on petals. This is one of the rarest and loveliest in our list.

\section{WURTEMBERGIA}

Each $\$ 1.00$

Enormous cerise scarlet; very tall growing. An outstanding flower, attaining almost unbelievable size.

\section{"THE NEW POPPIES"}

\section{Condensed from an Article by A. E. Curtis of Cincinnati and published}

in "The Flower Grower".

In describing the Poppies of the past season one's judgment can be based only upon the plants seen. The difference betweer an extra well-grown specimen and one that has done poorly is about fifty per cent, so if $\mathrm{i}$ praise highly some variety that has seemed only ordinary, it may not be so much a difference of opinion as a difference in the specimen seen.

We will start with the deepest reds. TRILBY I still feel holds her own. She is large, tall and stately, a real queen. WURTEMBERGIA is still the largest and finest medium red with the exception of CAVALIER, which is very similar but will grow even larger and finer. In the scarlet or flame red class, MANDARIN is a becuty, being one solid color without a blotch. PROSERPINE with an extra large black blotch though nearly the same color gives an entirely different effect.

Now a word of caution in regard to planting your reds. Be sure to keep your scarlet and even the medium red of WURTEMBERGIA away from the deep tints, or by contrast they will look like just another orange poppy, while by themselves or with the right surroundings they are brilliant flame or cerise red beauties.
The orange or red orange (often spoken of as a brick red), the Poppy of our grandmothers' day, will not need any comment. There are many large named varieties, in fact some of the largest, but it is a color hard to harmonize with the rest of the garden and the newer, clearer and more harmonious colors are so much handsomer that few will want to plant the former.

For those wanting a profuse blooming dwarf pink, WATTEAU (flesh-coral) is a little gem. The great majority of pink Poppies are salmon pink and there are probably fifty good Poppies in this color class. Two more pinks I would not be without are JEANNIE MAWSON and MRS. I. HAWKINS. A bed of either of these will stay in bloom for twentyone days while the average period for all others that I have checked is only ten days.

We now come to series of pastel shades which I wish to designate as cutting Poppies. When they first open they are very beautiful and if cut and brought into the house they hold their beauty; but left outside, they fade to colors that are anything but beautiful. For some reason the lilac and purple dyes in the Poppies do not stand the sun. One Poppy in this class deserves special attention - EN CHANTRESS, a tall, large and a beautifu. lilac rose. It is one of the finest Poppies ever seen when it opens, but, alas, fades to a colorless flower unless taken into the house.

All those who come to my garden want to see a white Poppy and when they are shown one, they are disappointed, and personally I do not care for them. What I want in Poppies is color. The whites are the only Poppies that do not grow well for me. Possibly they resent the fact that I do not admire them. PERRY WHITE is usually considered a poor doer. BARRS WHITE and PERRY'S BLUSH are probably the best. I have used my own near whites, PEARL PINK and PEARL QUEEN, which are hardy and strong growers. One caution is necessary with these. Plant them with blue Iris or Delphinium, for if planted near pink or red flowers they will appear a grey white by contrast and the same caution applies to PERRY'S BLUSH.

When it comes to color descriptions of Poppies, there is a great variation and on some varieties every description differs. I have described the color so it would be best visualized by the greatest majority of gardeners, but some kind of a Poppy Society is needed to standardize color description and to straighten out the variations that now go out under one name.

\section{THE FRESHMAN COLLECTION Six for $\$ \mathbf{2 5 0}$}

\section{LORD LAMBOURNE PERFECTION PROSERPINE}

\section{QUEEN LOUISE WURTEMBERGIA WATTEAU}

\section{THE POST-GRAD COLLECTION Seven for $\$ \mathbf{5 0 0}$ SPLENDOUR
TRILBY
RED LACQUER}

NOTE: Oriental poppies are best transplanted when perfectly dormant, in late August or early September. At that time they are one of the most unsightly of all plants, with no top at all and but little else than a few strands of bare roots of a fleshy nature. They will be packed in damp moss when you receive them . remove this and plant them with the crown an inch or less below the surface of the ground, water well immediately, and do not allow the soil to dry out. They will soon produce a mop of leaves and bloom gloriously the following spring. 


\section{9}

\section{Price Policy}

We have probably the largest planting of high class iris in this country, superior rhizomes that will even surpass your expectations. We can and do produce iris at as low cost as possible, quality considered, and in order to prove this, where price is a consideration, we will meet all competitors' retail catalog prices under the following conditions:

1. The dealer must be recognized as an actual commercial iris grower, advertising and doing business on a national scale.

2. We will recognize and meet only the RETAIL CATALOG price. All collection offers, private letter quotations, surplus lists, and prices of small neighborhood dealers can not be considered.

3. If you find our list price on any iris in this catalog to be higher than that quoted by some other dealer, simply mention his name alongside the variety on your order blank and pay us only the lowest quoted price. We will check all such for verification. We will not accept orders at less than 20 cents per variety.

4. For our own protection we must reserve the right to refuse to accept from anyone any order for any iris. This statement is made to avoid being taken advantage of by unscrupulous persons, although the offer is made in strict good faith. It must be realized, also, that late in the season, as is always the case, some items are bound to be sold out.
And if you will please

\section{READ THIS ...}

We shall both be spared

any misunderstanding about

\section{TERMS, TIME OF SHIPMENTS, ETC.}

Shipments: Will be made on bearded irises beginning about June 20th. If you wish your order sent later, or on any specific date, we shall carry out your instructions. Early shipments permit plants to become established before winter sets in, but rhizomes are not as large in July as they would be in August. We prefer to ship around July 10th as an ideal time.

ORIENTAL POPPIES AND HEMEROCALLIS WILL NOT BE SHIPPED UNTIL THE PROPER PLANTING SEASON, AROUND SEPTEMBER lst, OR SLIGHTLY LATER.

Positively no stock shipped during the spring months.

Transportation: Prepaid express or parcel post, whichever we deem most expedient. Be sure and state your express office, if different from postal address. We pack in dry excelsior in well ventilated cardboard cartons and guarantee safe delivery to point of address. All shipments are insured. Remember, we PREPAY all costs-the prices quoted herein are for delivery to your door.

\section{NO ORDER ACCEPTED FOR LESS THAN \$1.00}

Terms: Cash with order, either check, draft or money order. Enclosing cash in your letter may result in loss. $25 \%$ will hold until shipping date.

Discount: You may select additional plants to the value of $10 \%$ of your order if it totals $\$ 3$ or more. THIS DOES NOT APPLY TO COLLECTION OFFERS, however.

We Guarantee all bulbs and plants to be true to name, first size, free from disease and pests, and to reach you in live and healthy condition. We do not guarantee them to live or grow in your garden under conditions over which we have no control.

We have NEVER HAD AN IRIS BORER!

\section{COOLEY'S GARDENS}

Silverton, OREGON 

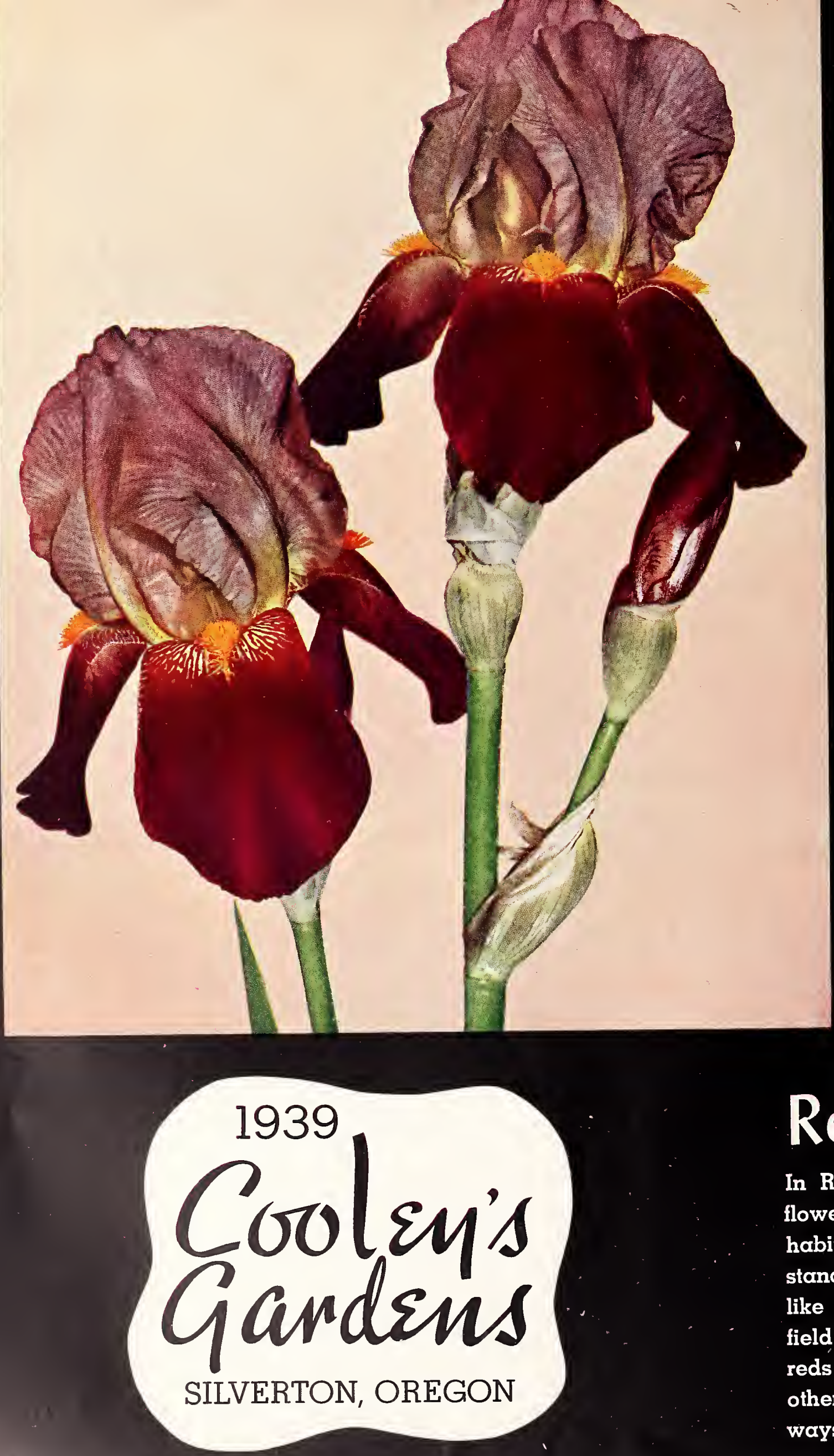

\section{Rebellior}

In Rebellion we have flower of faultless form an habit, vivid coloring, sul. stance which sheds wats like a duck's back. In field where reds and nea reds are crowding eac other for attention it is a ways singled out by critic 